\title{
Roles of stem cells in the treatment of Parkinson's disease
}

\author{
Y. Ebrahimikia ${ }^{1}, \underline{\text { Sh. Darabi }}{ }^{2}$, F. Rajaei ${ }^{2}$
}

\begin{abstract}
${ }^{1}$ Student Research Committee, Qazvin University of Medical Sciences, Qazvin, Iran
${ }^{2}$ Cellular and Molecular Research Center, Qazvin University of Medical Sciences, Qazvin, Iran

Corresponding Address: Shahram Darabi, Cellular and Molecular Research Center, Qazvin University of Medical Sciences, Qazvin, Iran

Tel: +98-28-33336001; Email: shahram2005d@yahoo.com

Received: 15 Apr 2018; Accepted: 13 Jun 2018
\end{abstract}

\section{Abstract}

Stem cells are undifferentiated cells with the ability to divide and differentiate into distinct cell types. The source of these cells is from embryos and adults, that each cell has its own specific characteristics. For nearly decades, experimental studies have been conducted to use these types of cells to treat various diseases. Parkinson's disease is one of the most common neurodegenerative diseases, resulting in a deficiency of dopaminergic neurons. Therefore, we study the role of stem cell therapies in the treatment of Parkinson's disease. Initially, 73 relevant articles selected from valid databases such as ISC, SID, Google Scholar and PubMed and the role of each type of stem cell in the treatment of Parkinson's disease was collected. Stem cells can be used in experimental studies regard to the unique characteristics and using different laboratory agents for any particular type of cells. Stem cells can provide an unlimited source of dopaminergic neurons for transplantation and improve motor behavior and symptoms of Parkinson's disease. Study and comparison of different types of stem cells refer to the more effective role of neural and umbilical stem cells in treating Parkinson's disease.

Keywords: Stem cells, Parkinson's disease, Dopaminergic neurons

Citation: Ebrahimikia Y, Darabi Sh, Rajaei F. Roles of stem cells in the treatment of Parkinson's disease. J Qazvin Univ Med Sci 2018; 22(4): 83-99. 
كاربرد سلولهاى بنيادى در درمان بيمارى پار كينسون

ياسمن ابراهيمى كيا'، دكتر شهرام دار ابيى، دكتر فرزاد رجايى'

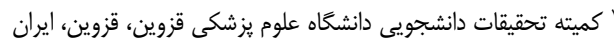

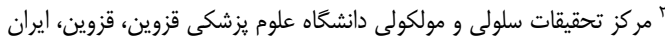

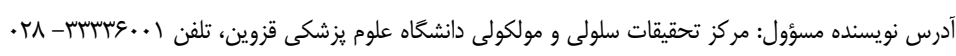

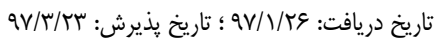

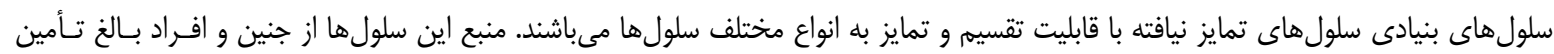

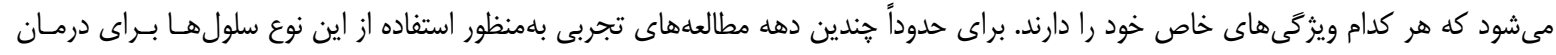

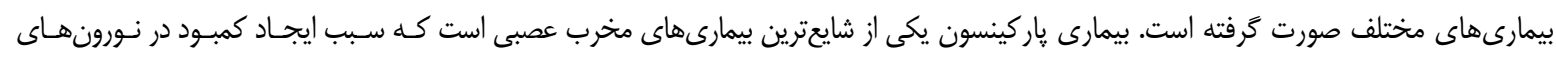

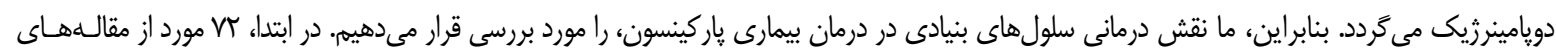

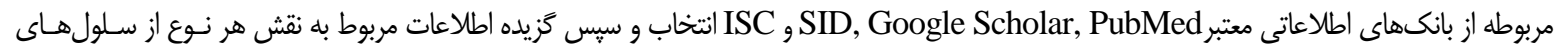

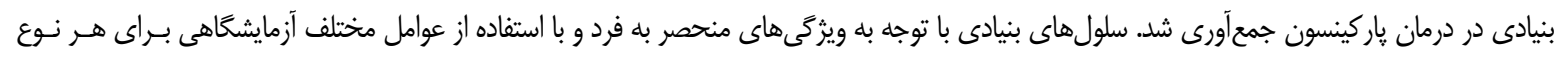

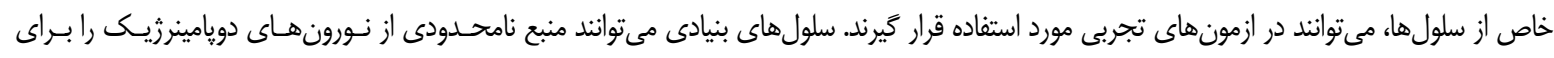

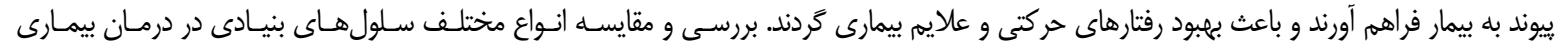

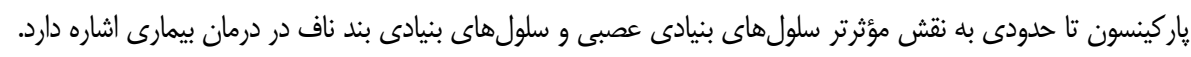

كليدوازهها: سلولهاى بنيادى، بيمارى ياركينسون، نورونهاى دويامينرزيك

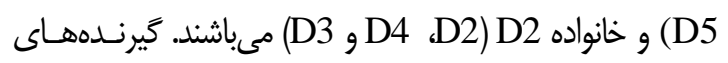
دويامينى نوع ب بـه فراوانس در طـول تكـوين در منـاطق

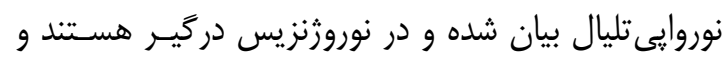

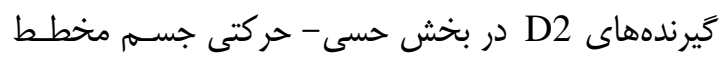

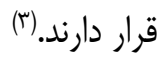

نقص در گيرندههاى دويامينى عامل مهمى در ايجـاد

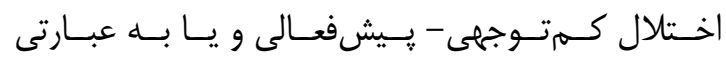
(Attention deficit hyperactivity disorder; ADHA)

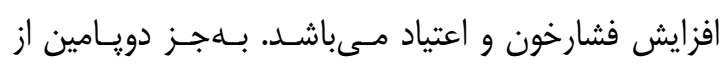

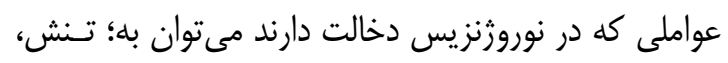

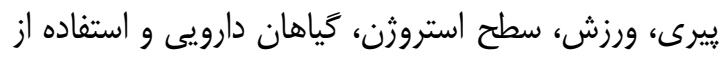

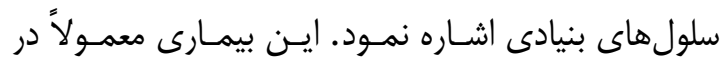

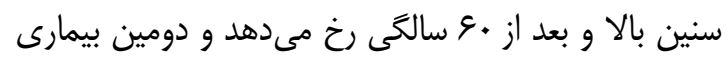

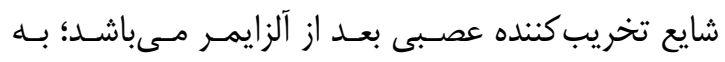

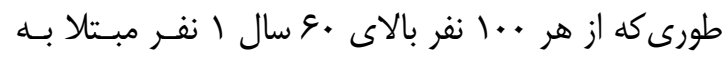

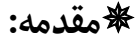

بيمارى پاركينسـون (Parkinson's disease; PD)

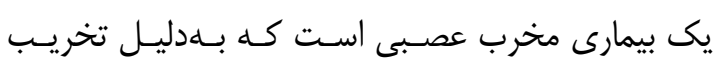

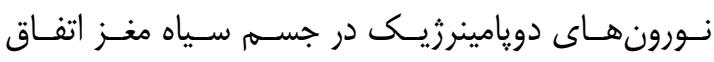

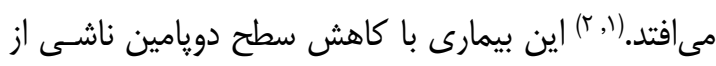

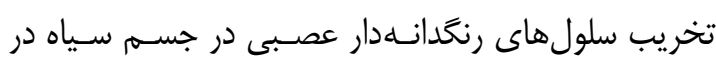
عقدههاى قاعدهاى مغز همراه است. فيبرها يـا مسـيرهاى

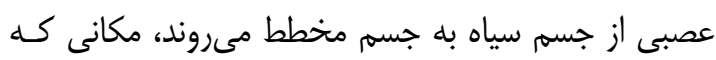
ييـامرسـانهـاى عصـبى (نوروترانسـميترها) در كنتــرل

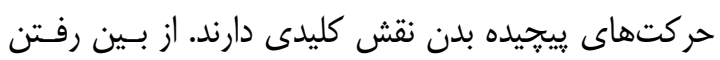

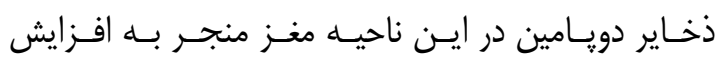

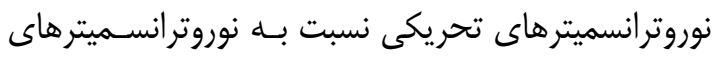

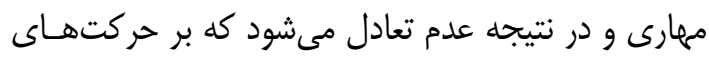

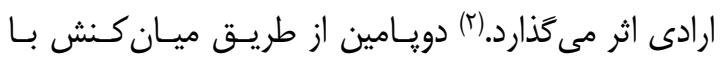

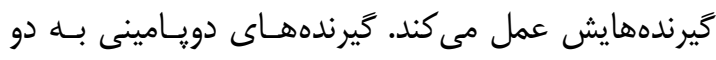

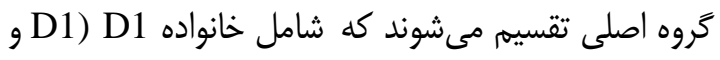


دادن به سلولهاى عصبى دويامينرزيك و از طريق تزريق

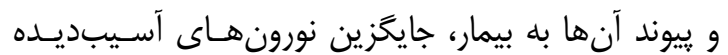

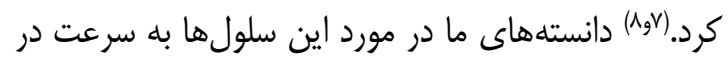

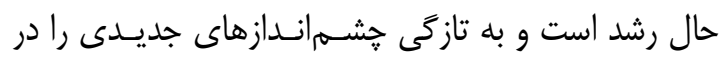
راهبردهاى ترميمى سيستم عصبى در جريان بيمارىهـاى جالى

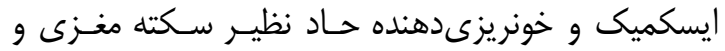

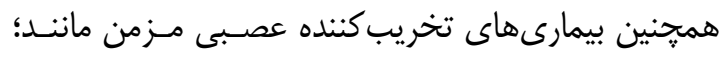

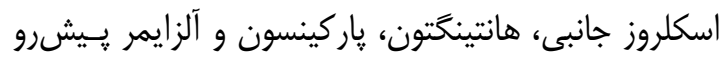

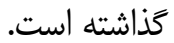
سلول درمانى بلوسيله سلولهاى بنيادى يك راهبرد جالب و مؤثر در درمان بيمارىهاى عصبى است و تاكنون

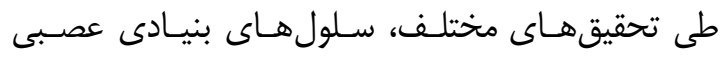

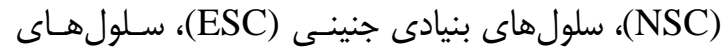
بنيادى مزانشيمى (MSC) و سـاير سـلولهـا در درمـان

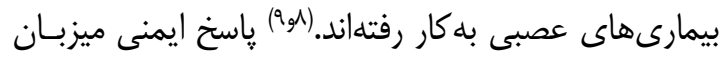

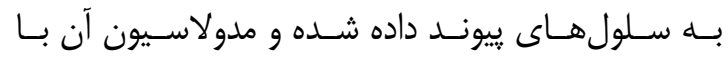
درمانهاى ايمنى بدن مىتواند بر موفقيت درمـان سـلول براى PD اثر بخذارد. ياسخ ايمنسى مسىتوانـد فراينـدهاى

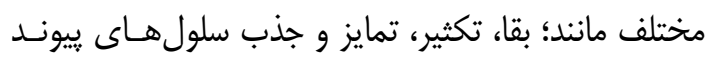

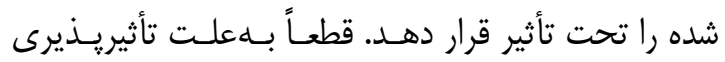

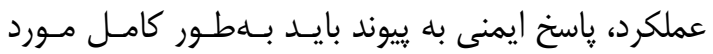

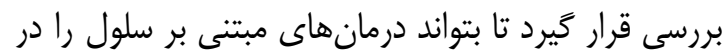

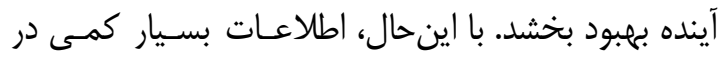

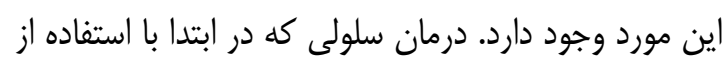
بافتهاى جنينى و البته با وجود محدوديتهايى مرتبط بـا

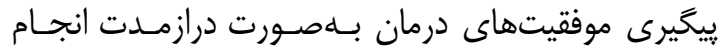

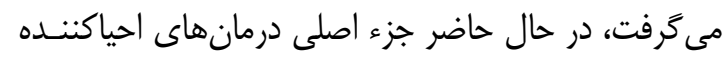

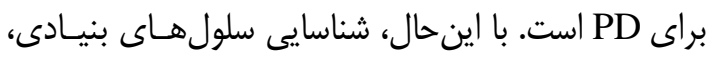

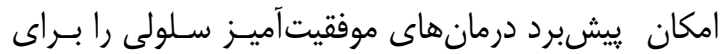
بيمارىهاى عصبى افزايش مىدهد. (9.

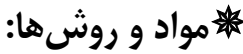

در اين مطالعه با مرور بيش از •V مقاله از بانكهــاى اطلاعاتى معتبر مانند SID ، Google Scholar PubMed
اين بيمارى است. البته اين بيمارى در افراد جوانتـر هــم

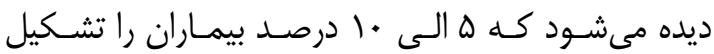

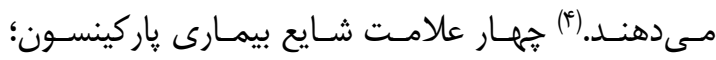

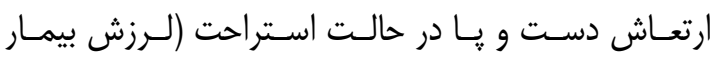

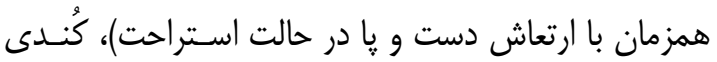
حركتها، سختى حركتها، خشك شــن دسـت و و يـا يـا

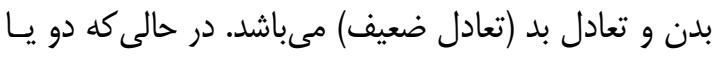

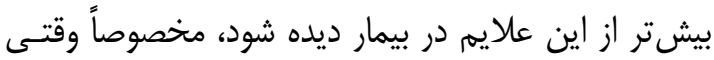
كه در يك سمت بـيشتـر از سـمت ديخـر ريديـدار شـوده،

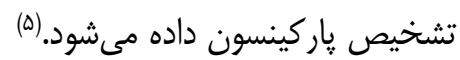
در مراحل اوليه بيمارى، ارتعاش اندام ملايم و معمولاًا در يك طرف بدن وجود دارد و احتياجى به درمان ندارد اما با بيشرفت بيمارى فردى كه دست لرزان خود را در جيسب

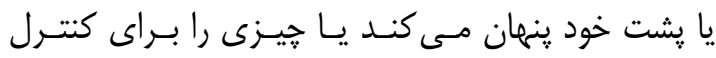

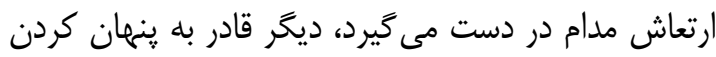

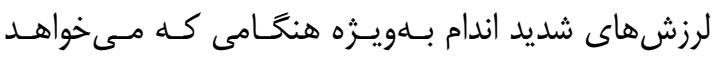

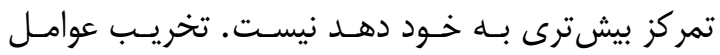
محيطى و زنتيكى مختلفى بر شـيوع ايـن بيمـارى مـؤثر

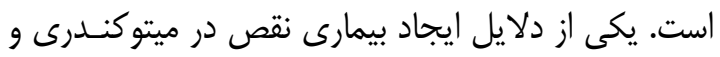

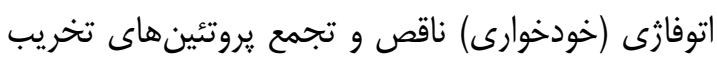

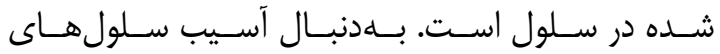
دويامينرزيكى و كاهش دويامين اختلالهـاى حركتس در در بيمار ايجاد مىشود. (9) براى درمان باركينسون داروهايى مثل؛

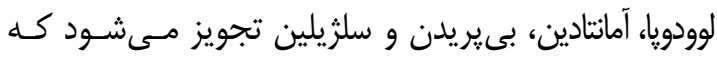
موجب بهبود فعاليتهاى روزانه بيمار مى گردد. با اين حال تجويز طولانى مدت لوودويا و ديخر اگونيستهاى كيرنده

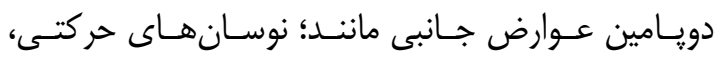
ديسكينزى و عوارض عصبى را شامل مىشود. (v) در سالهاى اخير درمان بيمارى ياركينسون بلهوسـيله

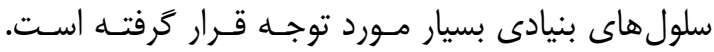

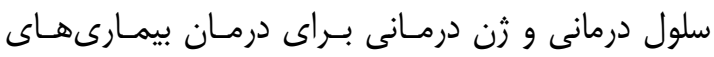

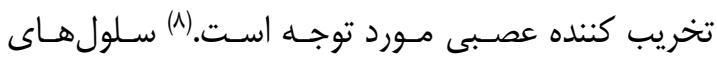

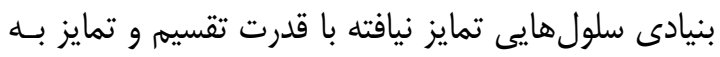
انواع سلولها مىباشند. اين سلولها را مىتوان بـا تمـايز 
نورونهاى DA با استفاده از اصلاحهاى ترانس ثنى سلولها

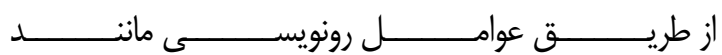
NURR1 (Nuclear receptor related 1 protein) LMX1 (LIM homeobox transcription factor 1, large) (B-cell lymphoma-extra BCL-XL, alpha)

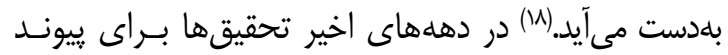
نورونهاى DA نشان داده است كه سـلولهـاى مشـتق

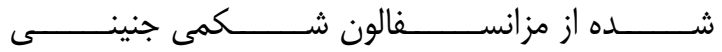
مسىتوانسد (fetal ventral mesencephalic; FVM)

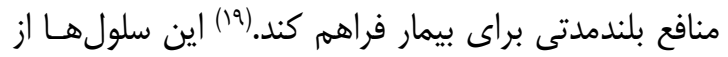

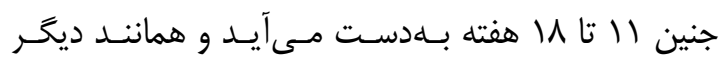
سلول هاى بنيادى جنينى خطر تومورزايى را به همر اه داه دارد.

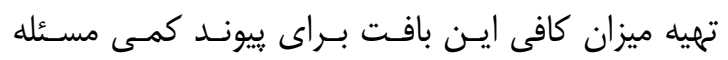

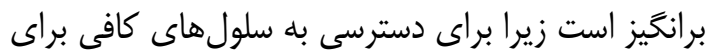

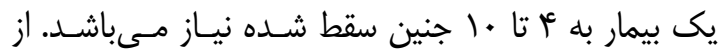

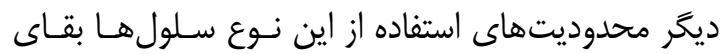
ضعيف نورونهاى دويامينرزيــ يِيونــد داده شـده اسـت.

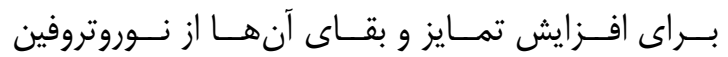

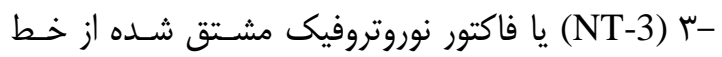

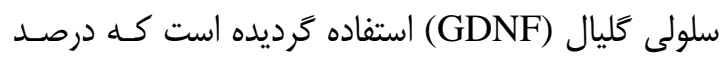

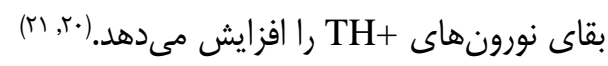
كزارش شده است كه كميلكس اصلى ساز كارى بافتى كه قسمت عمدهاى از سيستم ايمنى بـدن را در كارك (MHC)

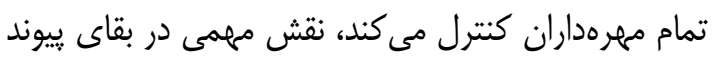

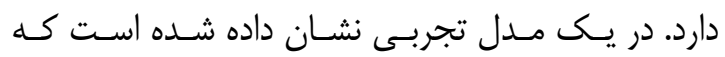

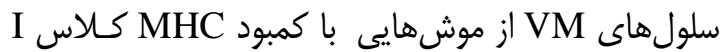

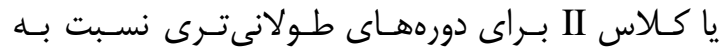

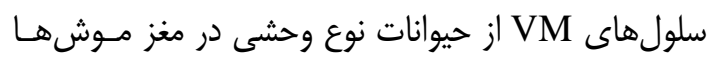

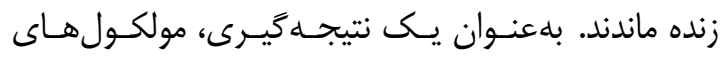

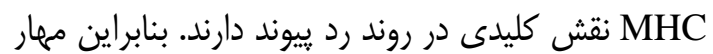

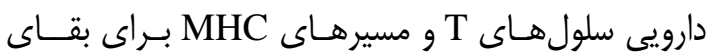
ييوندها در گونههاى مختلف ضرورى است. (T)

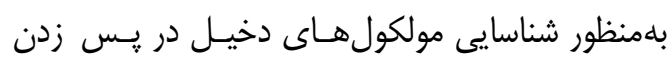

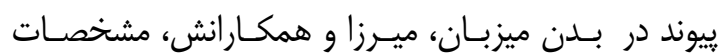

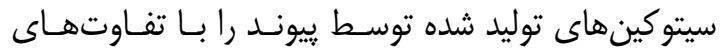

، Dopaminergic neurons بـا كليــدوازههــاى ISC و Stem cells و به بررسى منـابع مختلـف سلولهاى بنيادى بـراى درمـان PD و معايـب و مزايـاى آنهــا

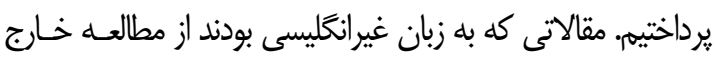

شدند.

سلولهاى بنيادى جنينى (Embryonic stem cells; ESCs)

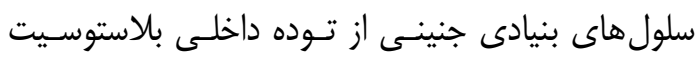

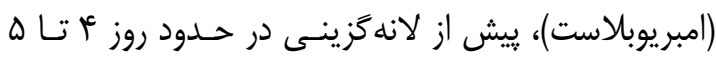

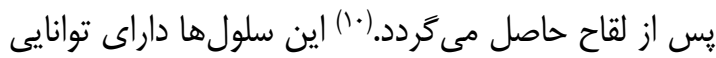

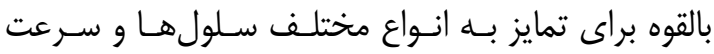

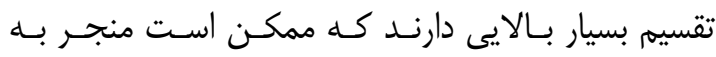

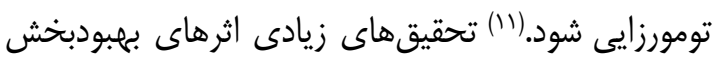
تزريق اين نوع سلولها را در درمان باركينسون نشان داده

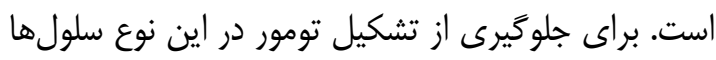

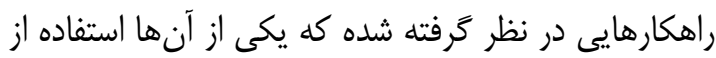
داروى متيومايسين است. يـك سـرى آزمايشهـاى in vivo (در داخل موجود

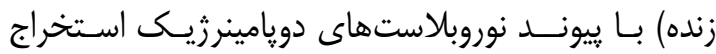

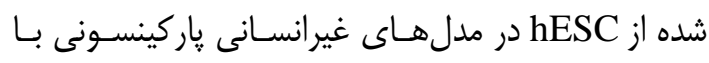

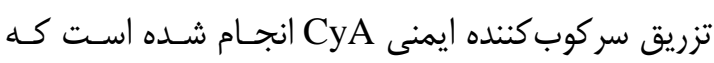
بقاى ييوند، عدم تشكيل تومور و بهبود موتورهاى حركتى

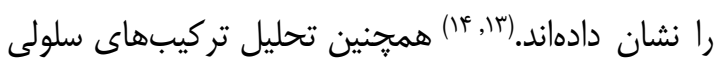
يبوند شده سـلولهاى (Tyrosine hydroxylase; TH) و مثبـت و و (Gamma aminobutyric acid; GABA مقدار كمى سروتونين مثبت را تشخيص دادهاند. درمان به

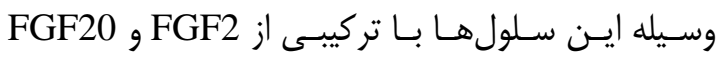

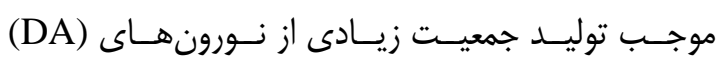
dopaminergic سلولهاى ES مىشود. (1ه, ع1) يك راهبرد براى بهدست آوردن جمعيتى از نورونهاى

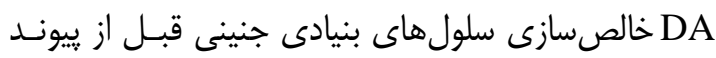

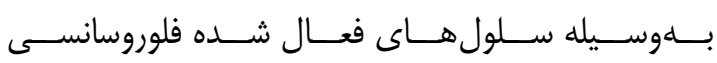
(fluorescence-activated cell sorting; FACS) مىباشد.(IV) جندين مطالعـه نشـان داده اسـت كـه توليـد 
حركت شدت يافت.(هه) علت آن مىتواند بهدليل نورونزايى

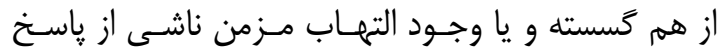

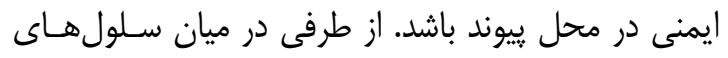

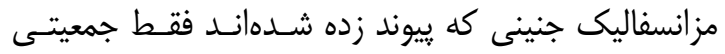
حدود ه تا + ا درصد نورونهاى دويامينرزيك وجـود دارد. بلمنظور برطرف نمودن اين مشـكل، محققـين بـا انجـام

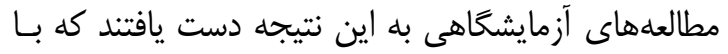

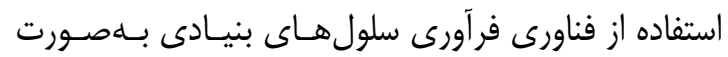
in vitro بنيادى عصبى و سلولهاى بنيادى مزانشيمى نيز مىتوان

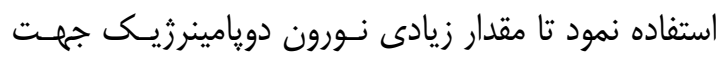
ييوند به بيماران يار كينسونى بهدست آيد.(צا)

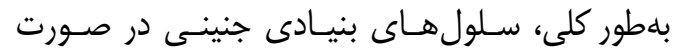
كنترل تقسيمهاى يـى در يـى و جلـوكيرى از تومـورزايى آنها مى توانند در درمان ياركينسون مثمرثمر واقع شـوند. البته ملاحظههاى اخلاقى نيز بايد در نظر كرفته شوند.

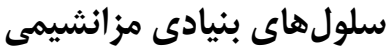
(Mesenchymal stem cells; MSCs) از مهمترين سلولهاى بنيـادى بزرخسـالان كـه امـروزه

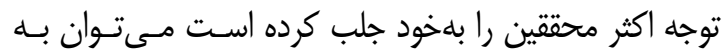

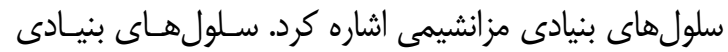
مزانشيمى از منابع مختلفى مانند؛ مغز استخوان، پالٍ دنــاني،

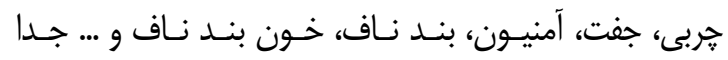

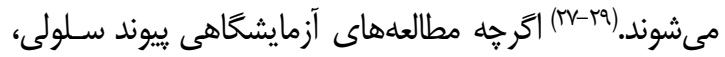
نتايج اميدبخشى را نشان داده است، اما سلولهاى بييوند شده

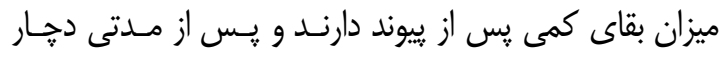

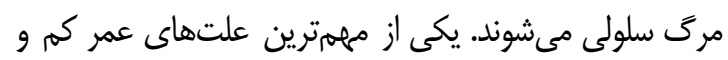

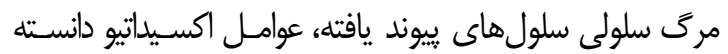
شده است. در اين زمينه كَفته شده كه راديكالهـاى آزاد اكسـيثن ناشى از هاييوكسى سلولى و ترومايى كه در طى آمادهسازى و يبيوند

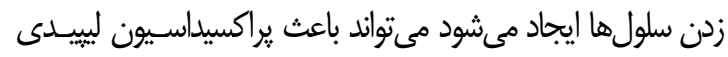

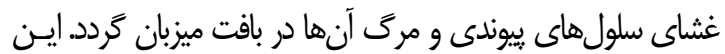

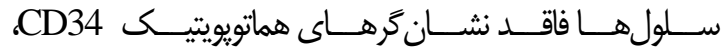

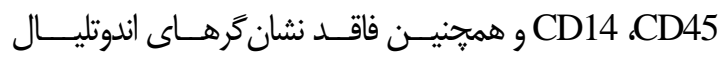

ايمونولوزيكى در حيوانات بدون سـركوب ايمنسى بررسى

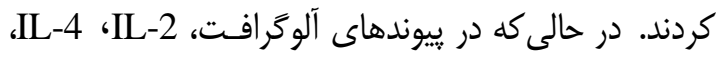
TNF-alpha و IL-lbeta

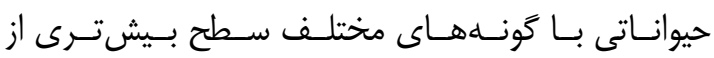
سيتوكينهاى يروتئينى التهابى در زمانهاى مختلف يـس

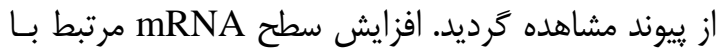

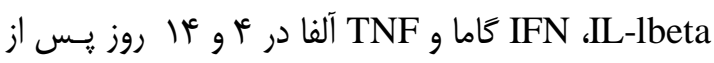

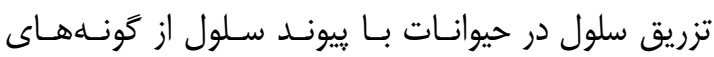

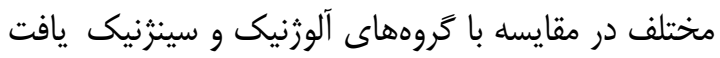

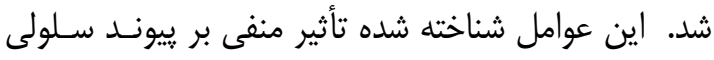

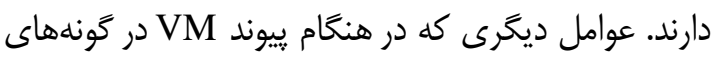

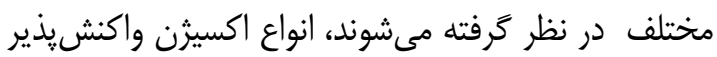
و نيتريتهاى مشتق شده از ميكروكلياهاى فعـال هسـتند

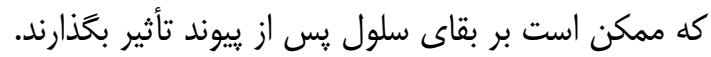

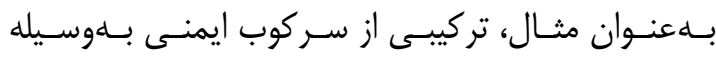

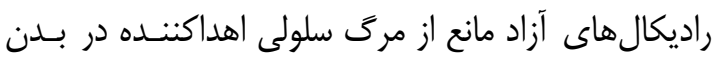

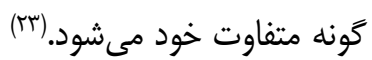

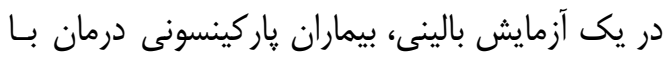

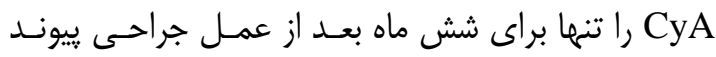

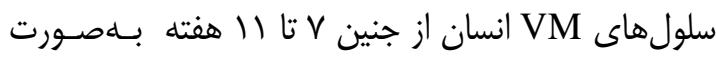

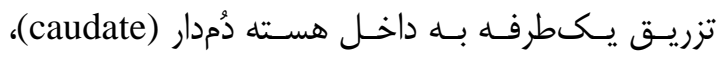

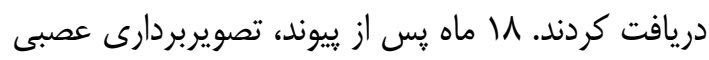

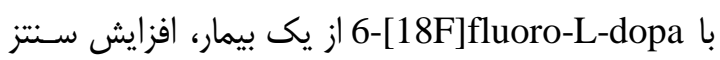

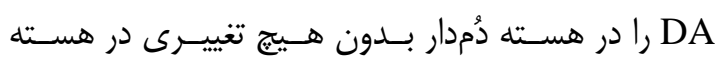

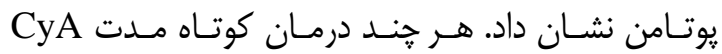

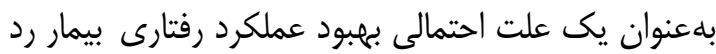

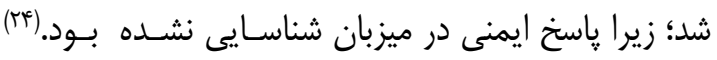

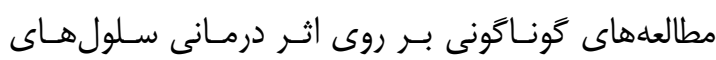

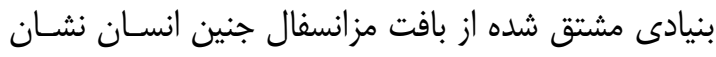

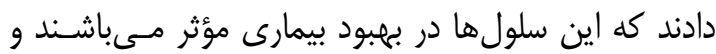

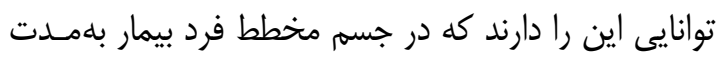

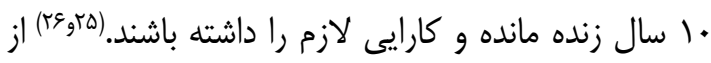

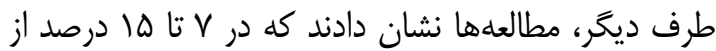

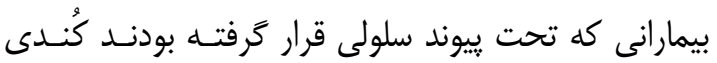




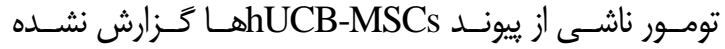

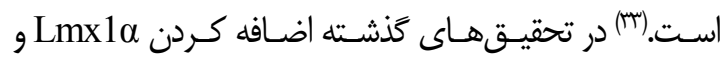

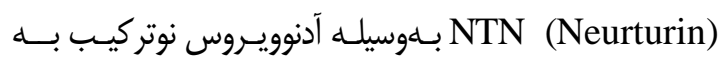

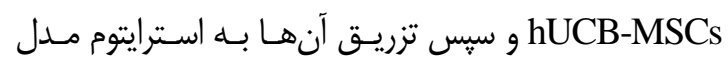

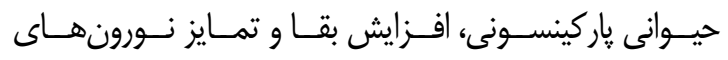
دويامينرزيك را نشان داده است.

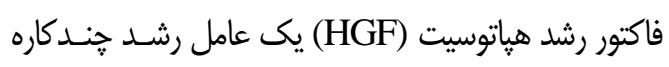
است كه توسط سلولهاى استروما توليد مىشـود. ايـن فـاكتور

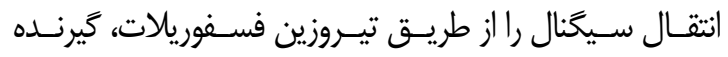
خـود فعـال (tyrosine-protein kinase Met) c-Met

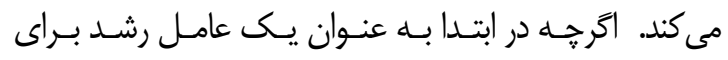

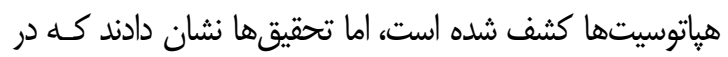

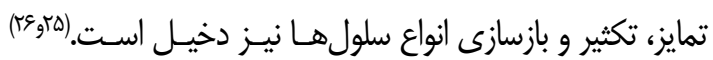

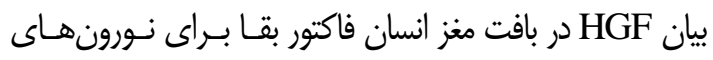
حسى و حركتى مىباشد. HGF مس تئوانـد در يـاتورنز بيمـارى

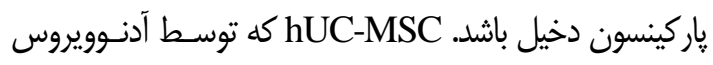

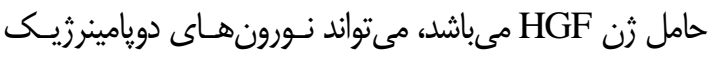

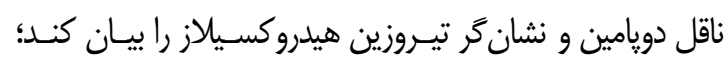

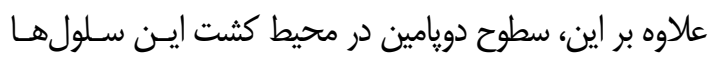

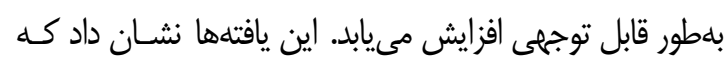

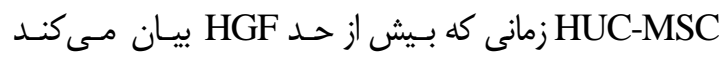

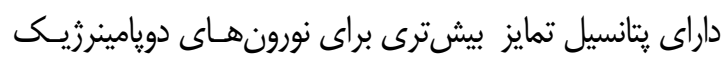

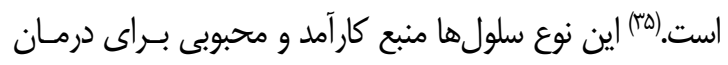
بيمارى هاى مختلف تخريب كننده عصبى بلحساب مى آيند. سلولهاى بنيادى مزانشيمى مشتق از مغز استخوان (Human bone marrow mesenchymal stem cells; hBM-MSCs) مغز استخوان استخوانهاى دراز بدن مانند فمور منبع

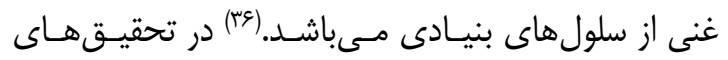

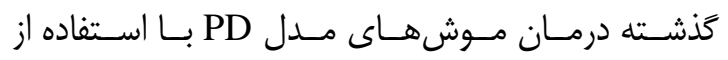
BM-MSCs (Brain-Derived Neurotrophic Factor; BDNF)

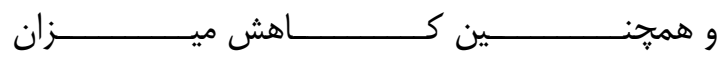
و TGF- $\beta 1$ (Transforming growth factor beta 1) MCP-1 (Monocyte chemoattractant protein 1) را كه از عوامل كنترل كنــــده واكـنش هـاى التهـابى بــنـن
(فاكتور ون - ويلبراند) هستند. VWF CD31 CD34

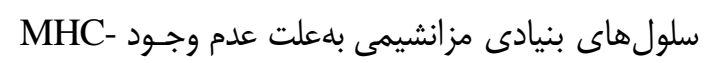

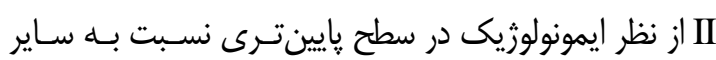

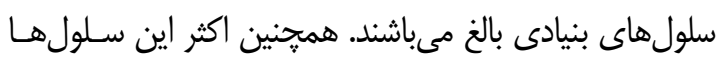

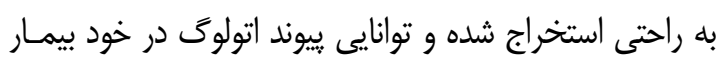

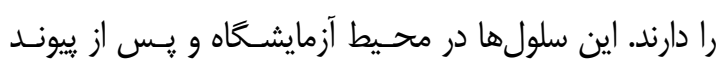

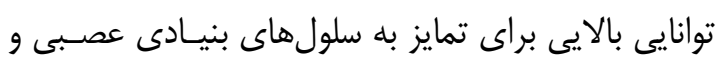

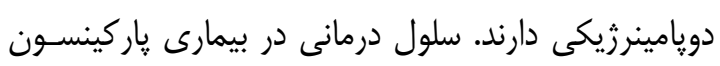

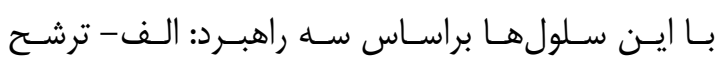

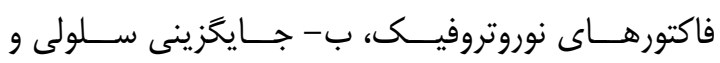
ج- اثرهاى ضدالتهابى استوار است. مطالعهها يس إز مركى

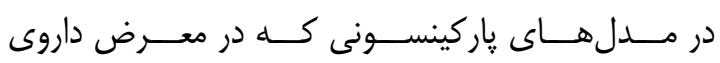
MTPT (1-methyl-4-phenyl-1,2,3,6-tetrahydropyridine) بودهاند، نشان داده است كه ميكروكلياها در سـلول فعـال

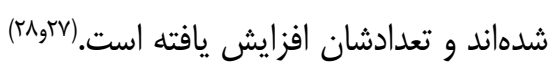

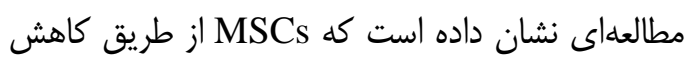

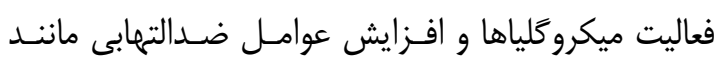
IL-6,IL-10 (Transforming growth factor $\beta$; TGF- $\beta$ )

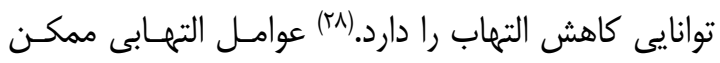

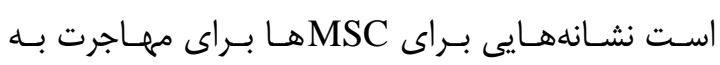

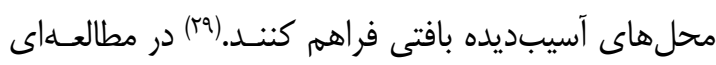

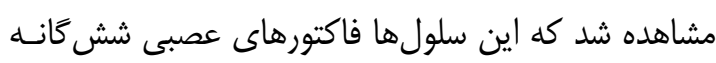
مانند GDNF

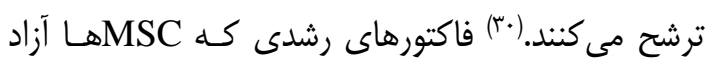

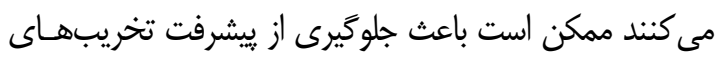

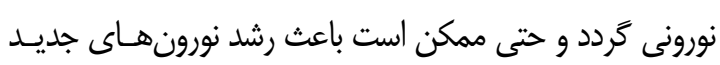

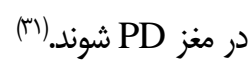

سلولهاى بنيادى مزانشيمى مشتق از بند ناف (hUC-MSCs; Human umbilical cord mesenchymal stem cells) سلولهاى بنيادى مشتق شده از بند ناف بهدليل دستيـابى

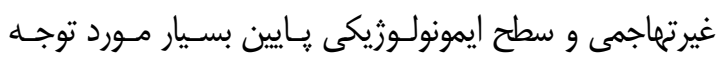

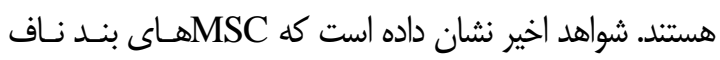

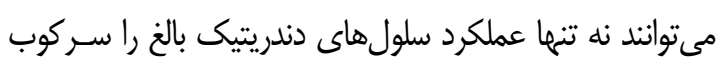

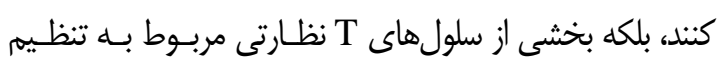

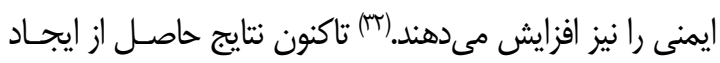




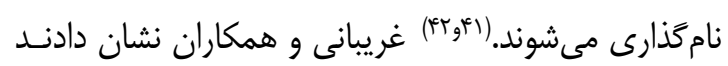

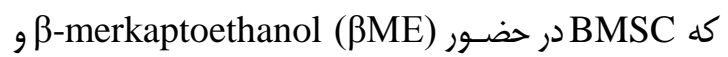

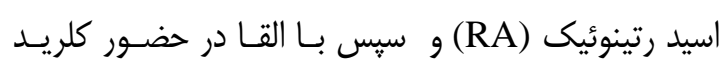

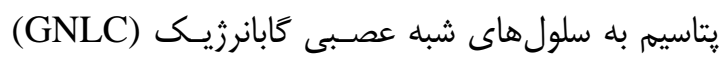

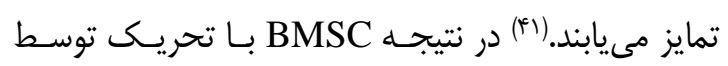

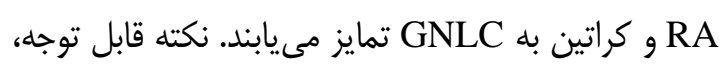

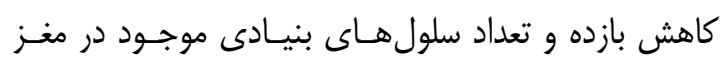

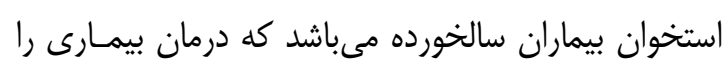

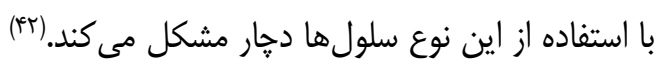

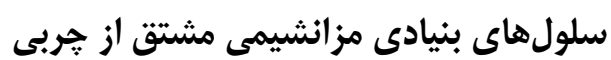
(hAD-MSCs; Human adipose mesenchymal stem cells) يكى از مشكلات درمان بيمارى ها بلهوسيله سـلولهـاى

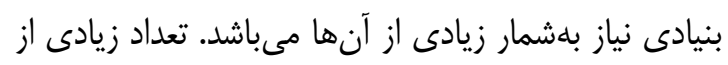

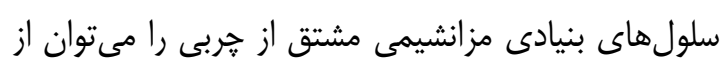

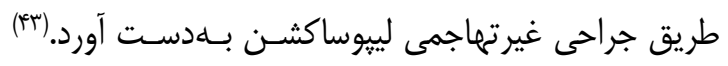

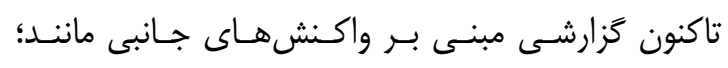

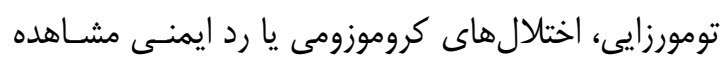

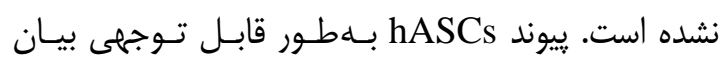

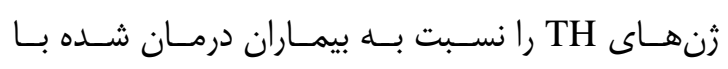

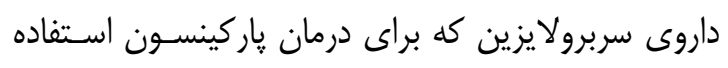

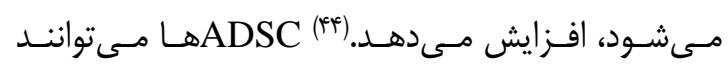
ROS (Reactive oxygen species)

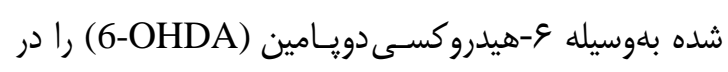

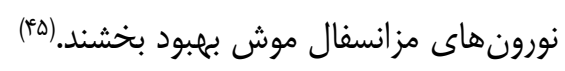

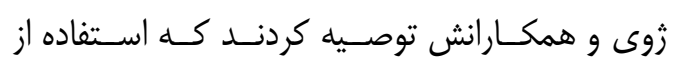

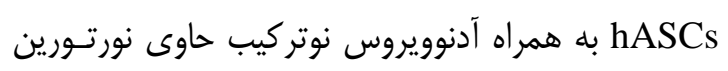

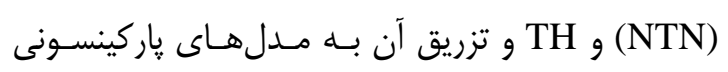

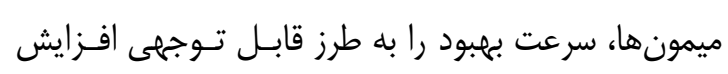

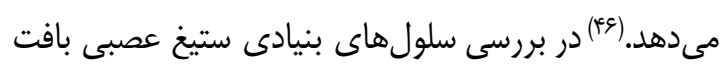

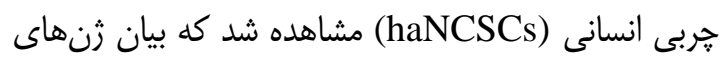
(octamer-binding transcription factor 4; OCT4) (Pron. nanOg; NANOG) ،(SRY-box 2; SOX2) و (Zfp-42; REX1) نسـبت بـانه بيـان آنهـا در (SRYs)

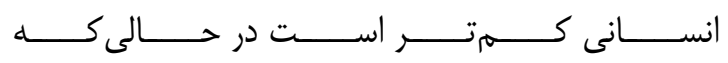

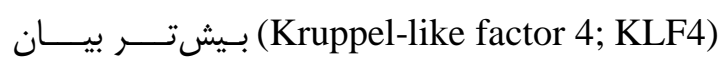

هستند نشان داده شده است. (rV) براى افزايش بقـاو وتمـايز

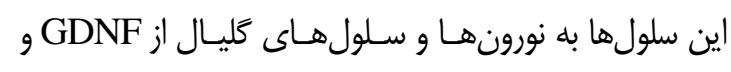

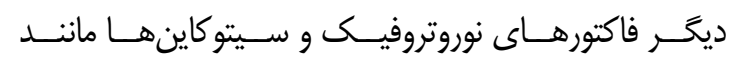
(CAMP response element binding protein) CREB

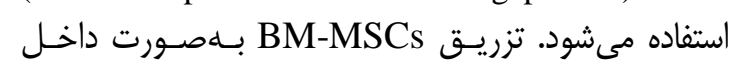

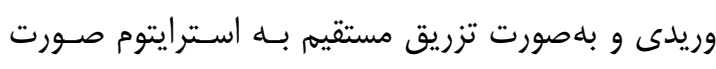

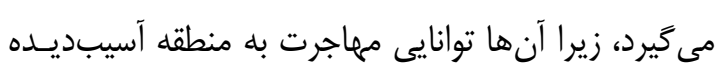

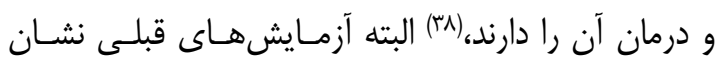

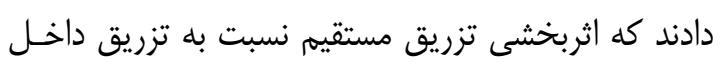

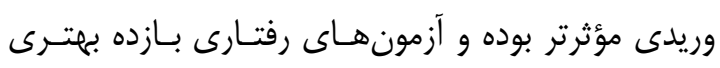

داشتند. (זq)

در مطالعهاى به جندين موش صـحرايى ياركينسـونى

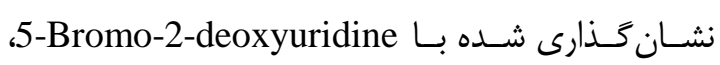
سلولهاى MSC به داخل جسمى سـياه (SN) در محـل تزريق

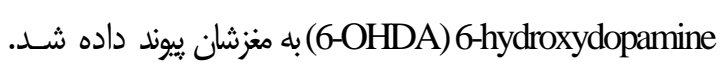

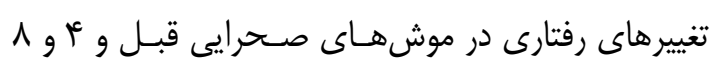

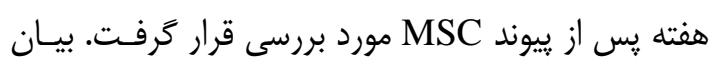

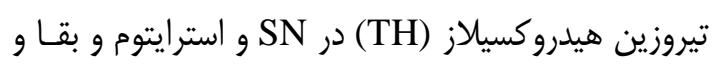

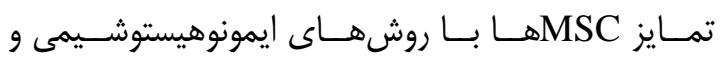

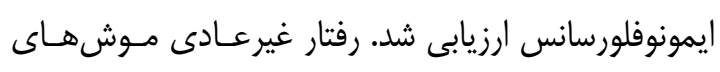
صحرايى PD يس از تجويز MSCs بهطور قابل تـوجهى

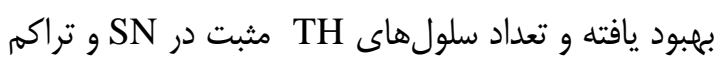

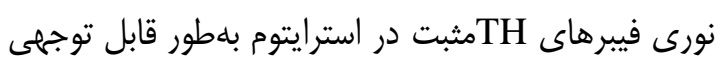
افزايش يافت. MSCهاى ييوند شده توانستند در مغز زنده

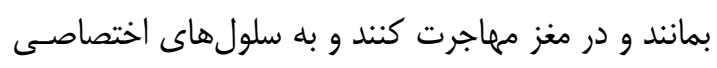

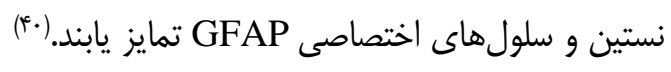

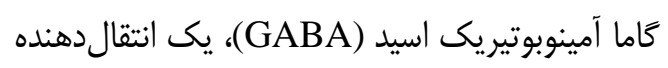
عصبى مهار كننده در سيستم عصبى مركـزى يسـتانداران

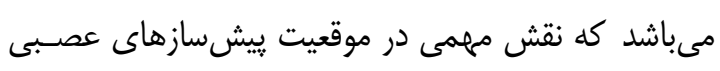

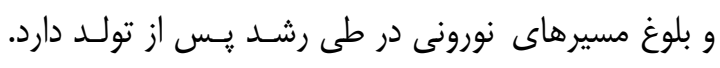

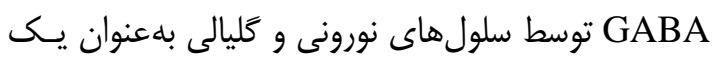

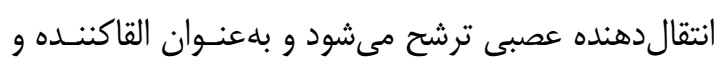

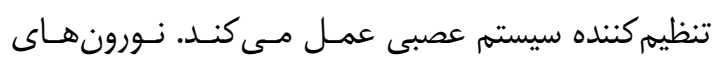
ترشحكنده GABA بلعنوان نورونهـاى GABAergic 
CD90 ، CD105 و OCT4 مثبــ CD44 هســتند و

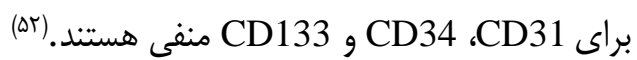

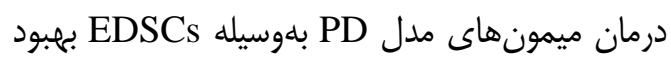

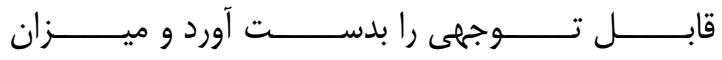

بعد از تزريق •V درصد (Homovanillic acid; HVA)

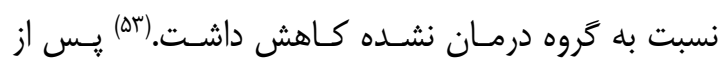

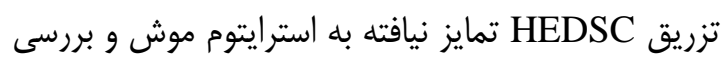
زنى مغز آن، سلولهاى انسانى در ناحيه تزريق و همجنين

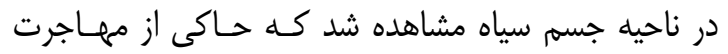

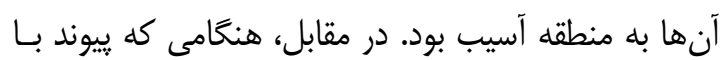

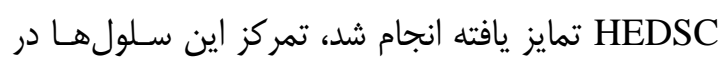

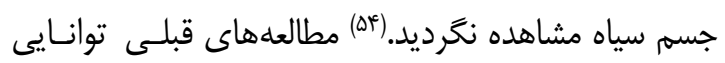

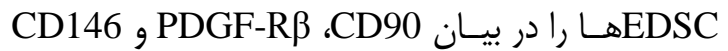
براى تمايز به سلولهاى شـبه نـورونى مترشـح دويـامين

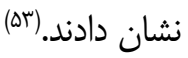

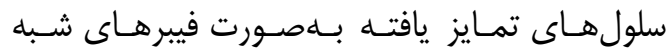

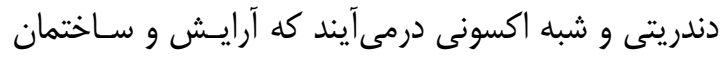

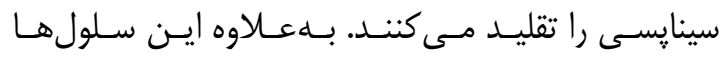

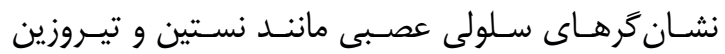

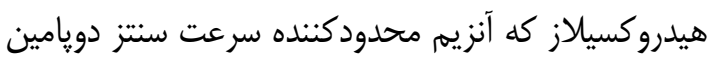

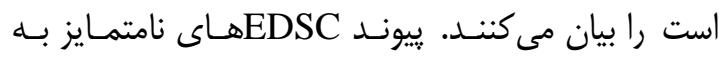
موشهاى صحرايى تحت داروى MPTP نشـان داد كـه

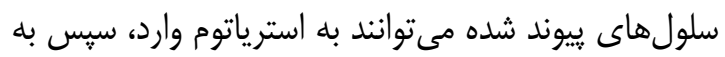

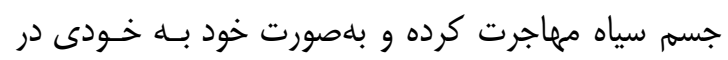
محيط in vivo تمايز و باعث افزايش غلظـت دويـامين و

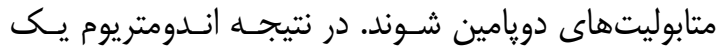
منبع مهم سلولهاى بنيادى با ظرفيت بازسـازى و تمـايز

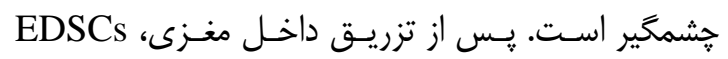
مىتواند در استر ايتوم جذب، به ناحيه آسيبديده مهاجرت، به سلولهاى TH مثبت تمايز يبيدا كرده و از نـورونهـاى

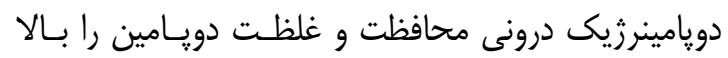

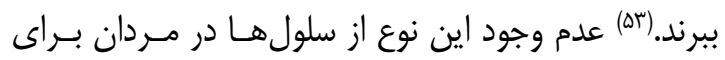

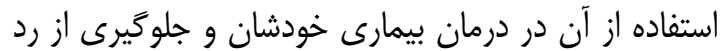
يبيوند در آنها از مسائل و محدوديتهاى موجان دوان دود در زمينه

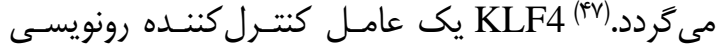

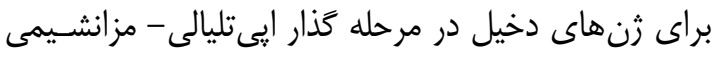

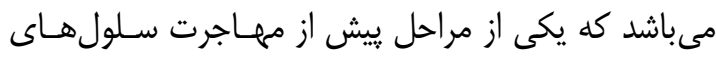

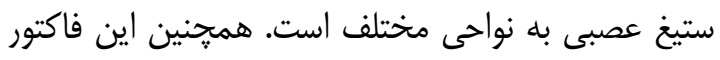

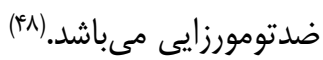
داراى يتانسيل تمايز קُند خطى بوده و مى تواند

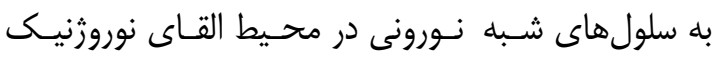

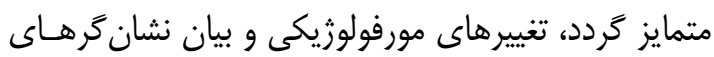

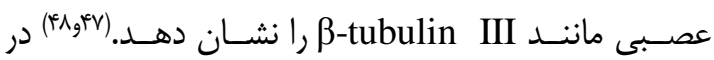
مطالعاى اثر ييوند داخل وريدى سلولهاى بنيادى مشتق

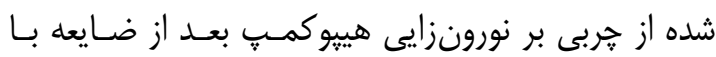

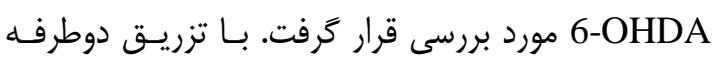
6-OHDA در SNc موشهاى صحر اييى نر نـزاد ويستـار

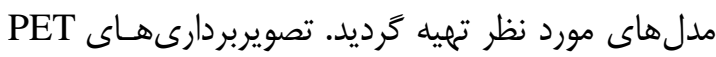

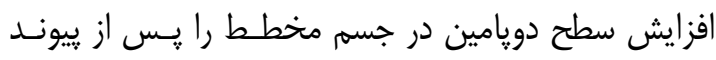

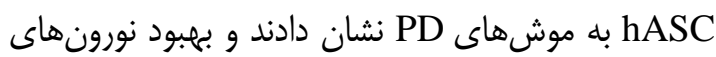

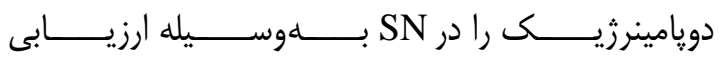

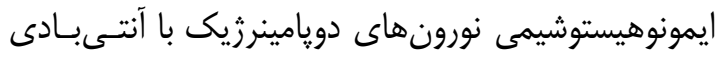

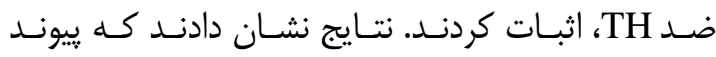

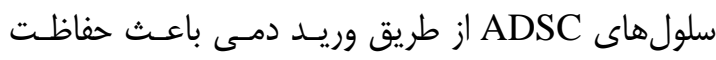

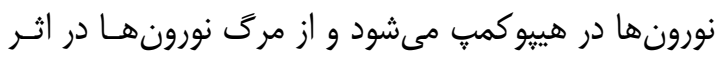

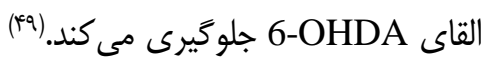

سلولهاى بنيادى مزانشيمى مشتق از اندومتريوم (Human endometrium mesenchymal stem cells; hED- MSCs) أندومتر يك منبع جذاب و جديد از سلولهاى بنيـادى

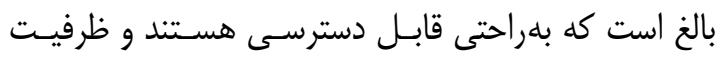

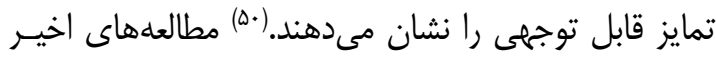

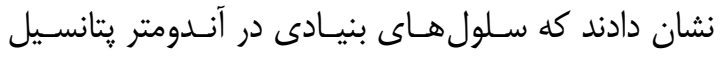

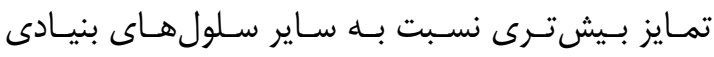

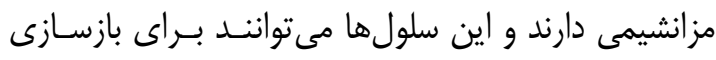

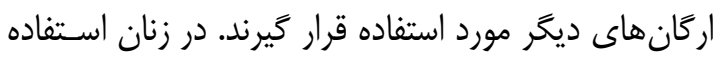

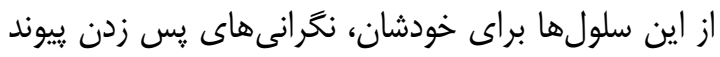

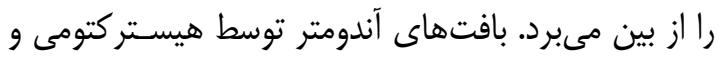

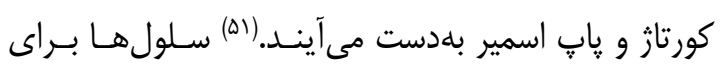




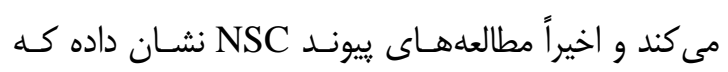

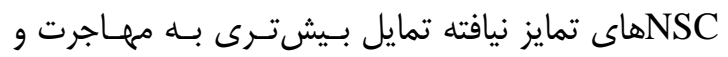

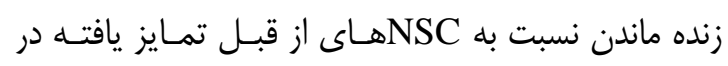

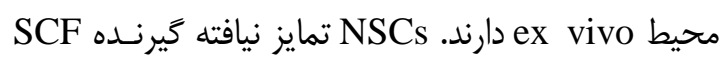

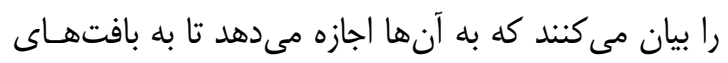

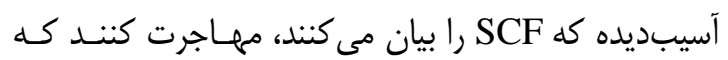

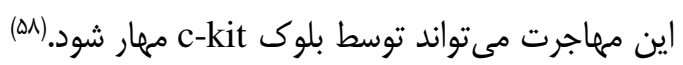

\section{بحث و نتيجه}

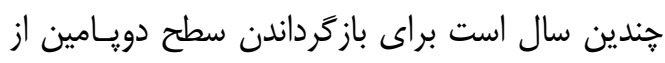

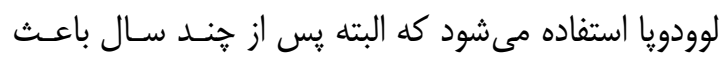

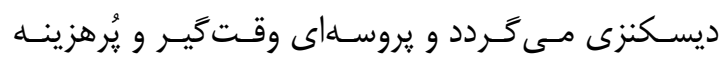

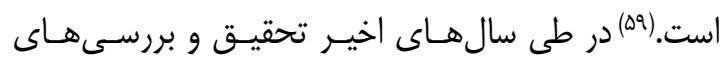

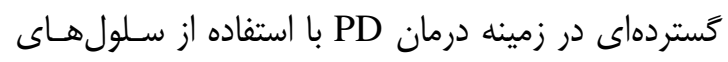
بنيادى در حال انجام است. راهبردهاى درمان با سلولهاى دماى دان

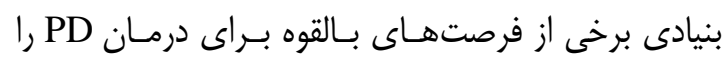

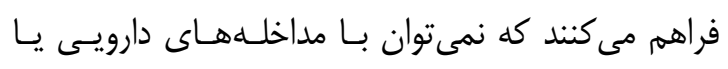

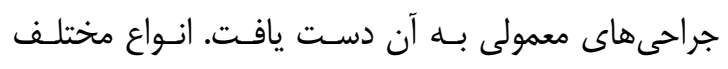

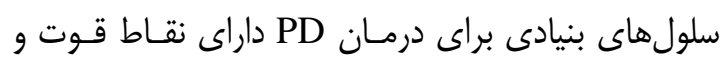
ضعف خود هستند (جدول شماره ()).
استفاده از اين نوع سلولها مىباشد.

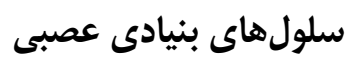

(Neural stem cells; NSCs)

نه نه تنها در مغز جنين، بلكه در مغـز بزرگسـالان

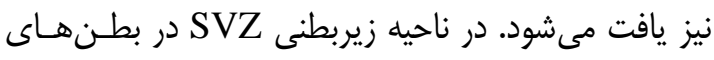

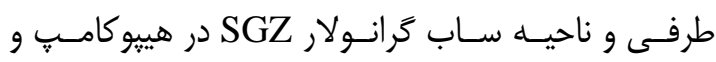

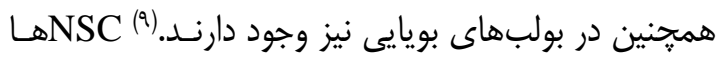

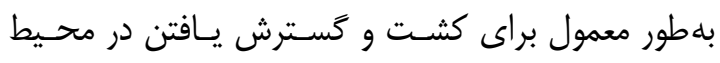

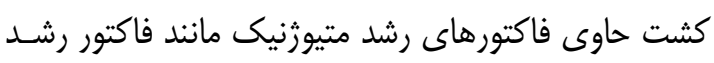

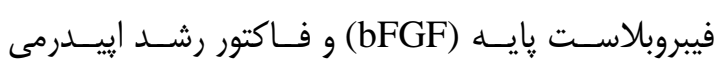
قرار مى گيرند. استخراج و كسترش مSCs (EGF)

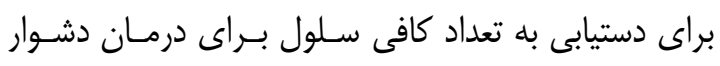

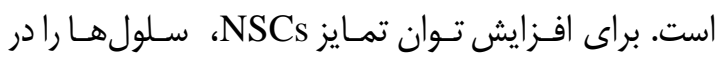

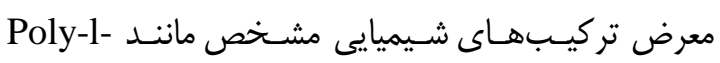
matrigel laminin ، Ornithin

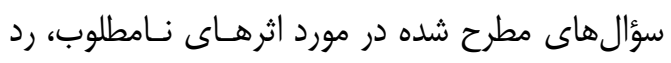

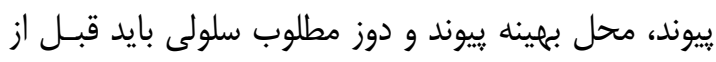

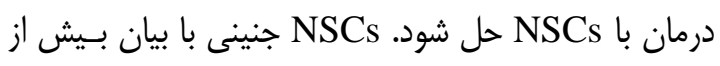
حد GDNF مىتواند باعث افزايش بقا و گسـترش اليـاف عصبى در مغز ميانى موش مدل PD شود. PSCs

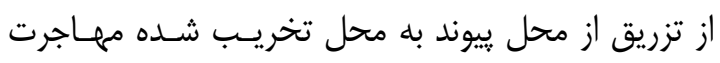

\section{جدول ا - انواع سلولهاى بنيادى، مزايا و معايب كاربرد آنها در درمان پاركينسون}

\begin{tabular}{|c|c|c|c|c|}
\hline منابع & معايب & مزايا & 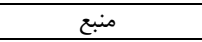 & 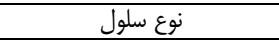 \\
\hline 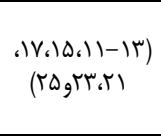 & 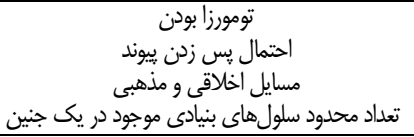 & 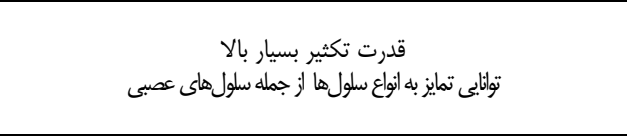 & إز إلاستوسيست سلو ، داخلى & (Embryonic stem cells) \\
\hline 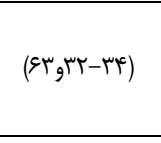 & تعداد محدود سلولهاى بنيادى موجود در يك & 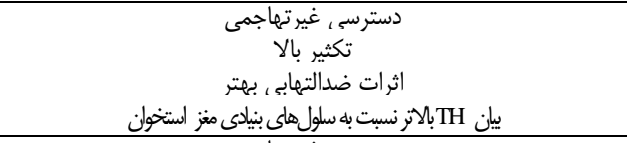 & 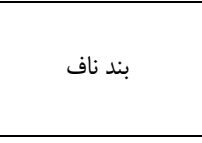 & $\begin{array}{l}\text { سلول هاى بنيادى بند ناف } \\
\text { (Umbilical cord stem cells) }\end{array}$ \\
\hline 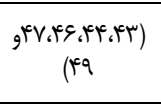 & قدمر سلولى كوتاهتر & 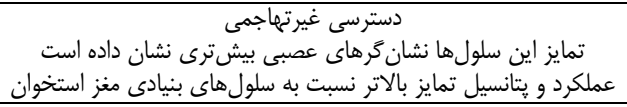 & بافت خربى & 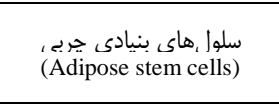 \\
\hline 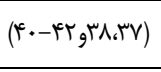 & كاهش تعداد اين سلولها در افر ادر ساد سالخورده & 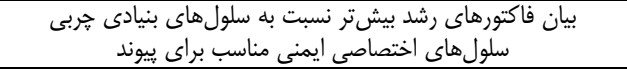 & مغز استخوان & سلو، هاى بنيادى مغز استخوار)، (Bone marrow stem cells) \\
\hline$(\Delta F, \Delta \cdot-\Delta T)$ & تعداد محدود سلولهاى بنيادى موجود در يك & 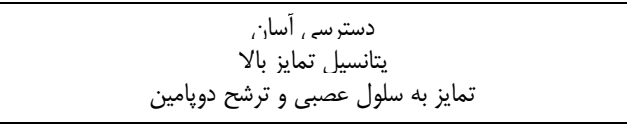 & بافت اندومتر رحم & سلولهاى بنيادى اندومتر \\
\hline 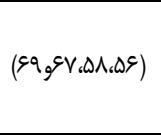 & 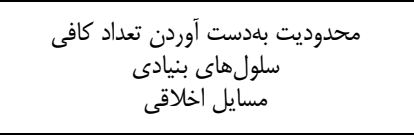 & 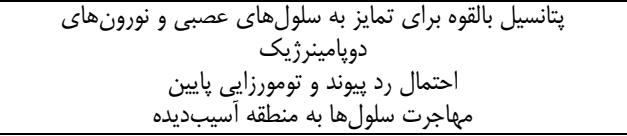 & بافتهاى عصبى مغز & سلولهاى بنيادى عصبى (Neural stem cells) \\
\hline
\end{tabular}


سلولهاى بنيادى مزانشيمى معمولاً بدون مشكلهاى تراى

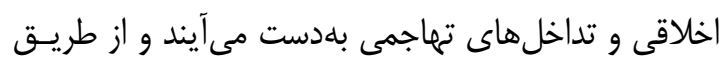

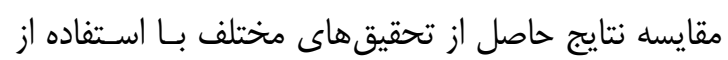

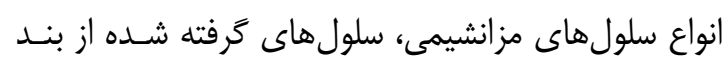

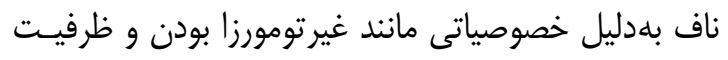

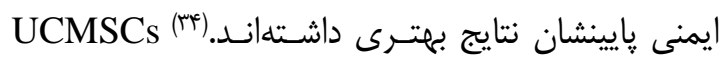

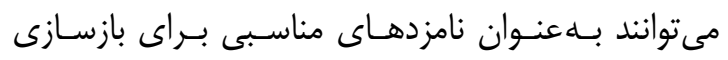

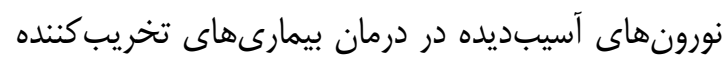

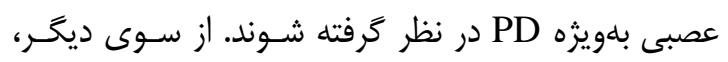

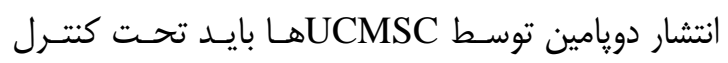

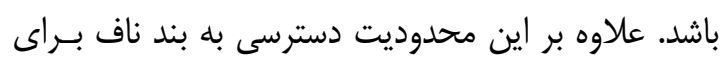
درمان بيمار نيز مدنظر مىباشد.

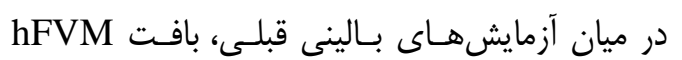
براى درمان PD موفقترين نتايج را به همراه داشته است.

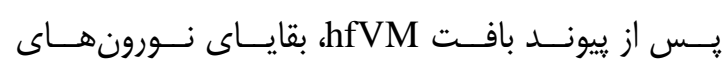

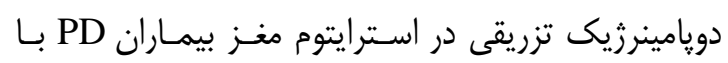

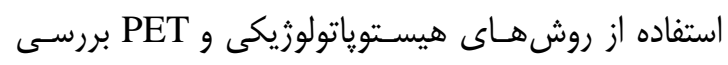
شدهاند. نتايج ايجاد اتصال سينايسى آوران و وابران ميـان

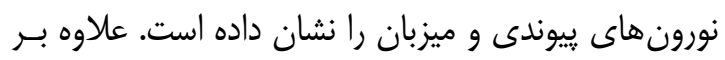

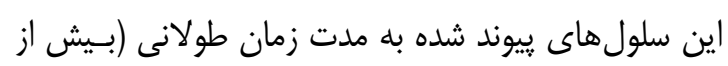

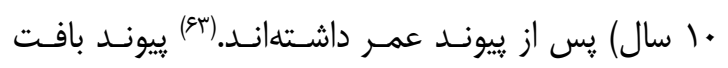

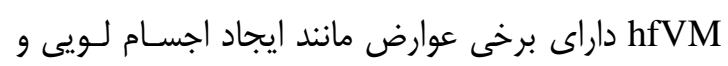

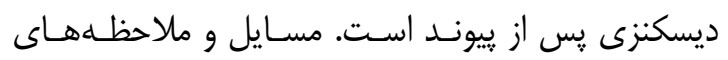

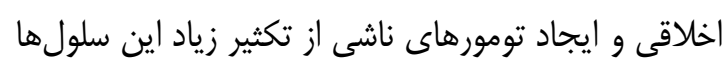

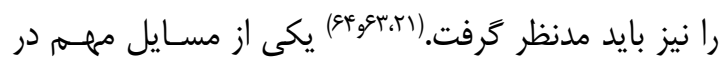

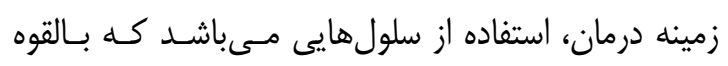

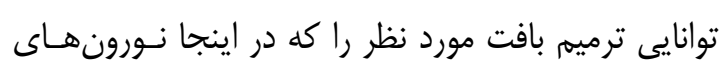

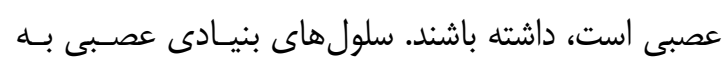

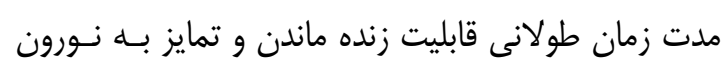
دارند. (\$ه)

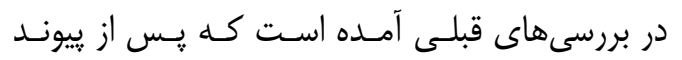

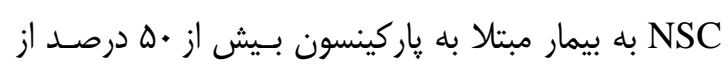

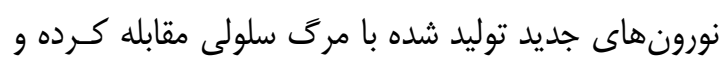

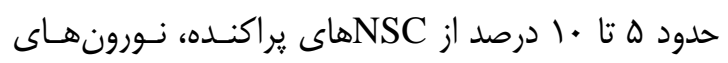

اخرجه درمان مبتنى بر سلولهاى بنيادى تـا حـدودى بر روى كنترل علايم PD اثر مى خذارد، اما ارزيابى عوامل

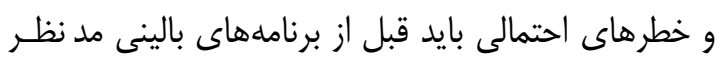

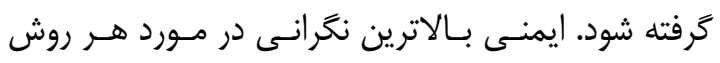

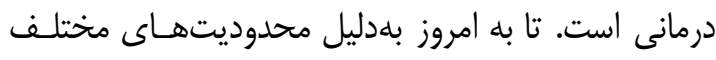

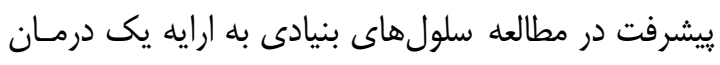

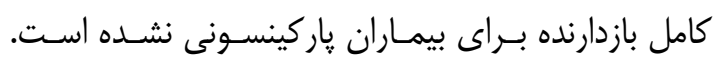

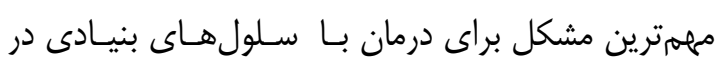

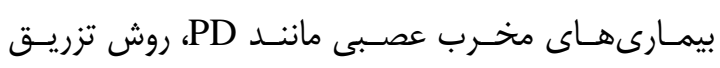

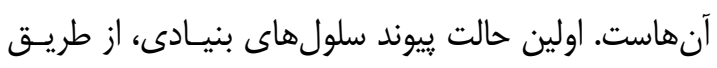

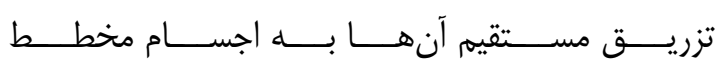

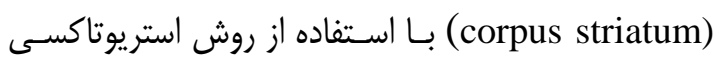

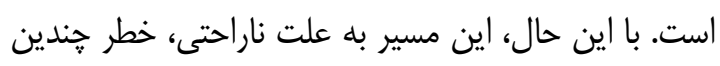

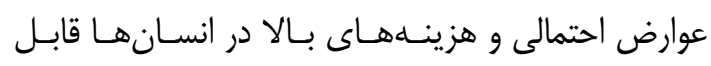

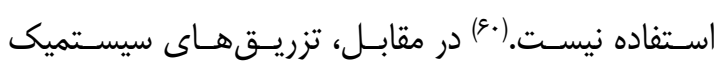

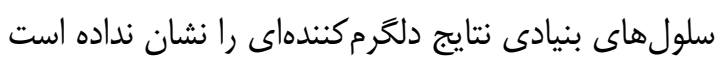

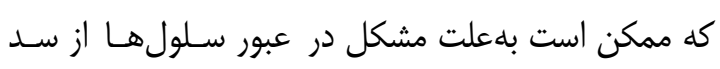

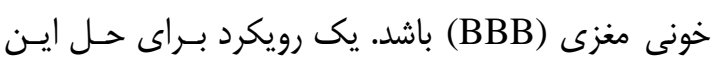

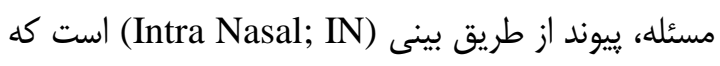

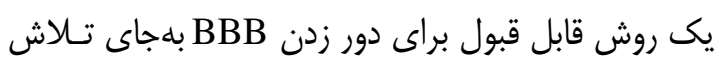
براى عبور از آن مىباشد. كذر بينى تنها اتصـال مسـتقيه

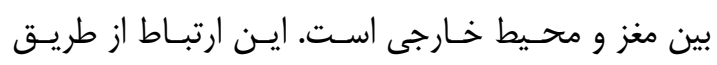

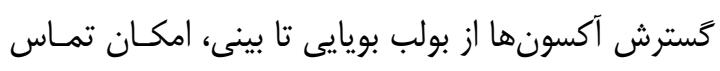

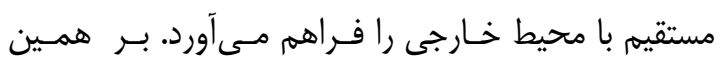
اساس، مسير IN براى تحويل عوامل مختلف برای درای درمان

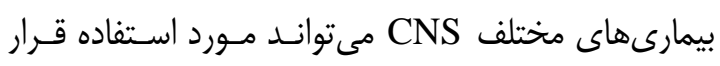

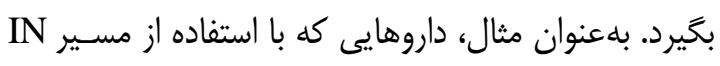

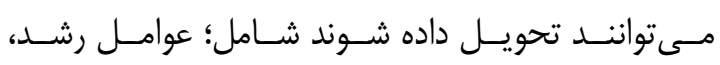

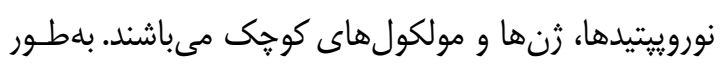

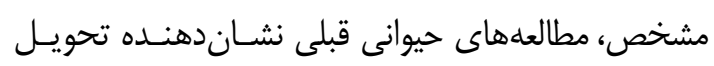

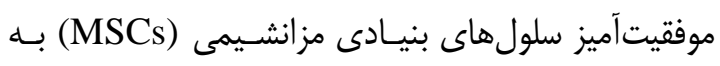
مغز از اين طريق مىباشد. علاوه بر اين، مدلهائ حين حيوانى

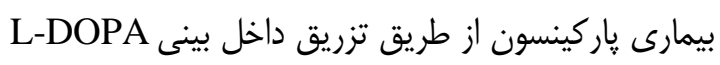

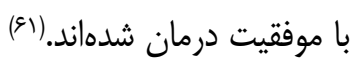


مى كذارند، خالشهايى براى تعريـف يـك درمـان خـاص

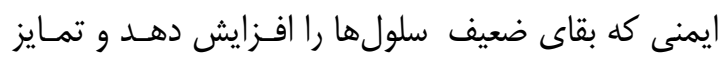

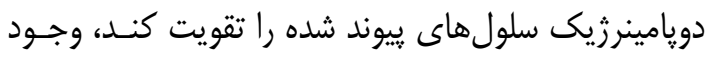
دارد.

با توجه به اينكه اثرهاى مربوط به ياسخهاى ايمنى در سلولهاى يِيوند شده، بسيار خشمخير اسـت، معتقـديم

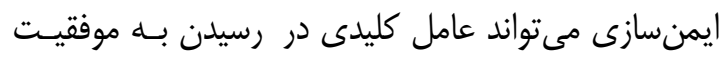

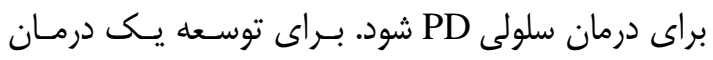
سلولى مفيد در درمـان PD، معيارهـاى انتخـاب بيمـار و و

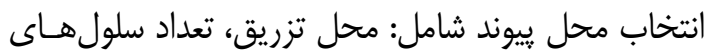

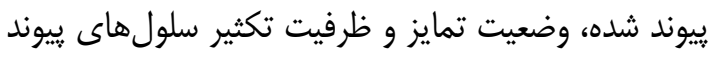

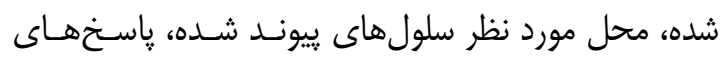
ايمنى ناخواسته، انتقال عوامل تهديد، شكل گئيرى تومور و

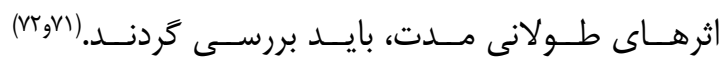

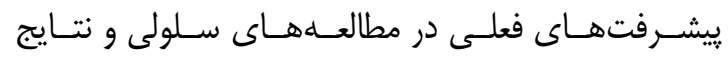

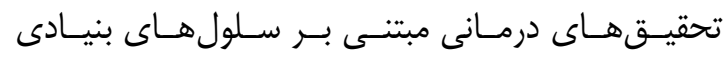

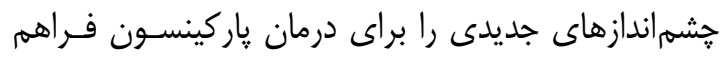

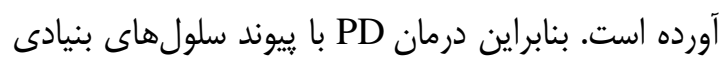

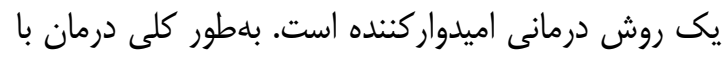

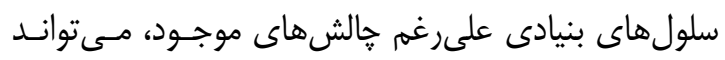

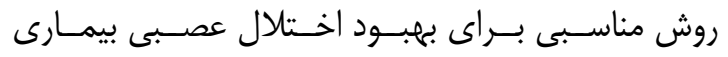

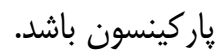

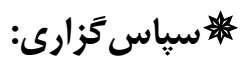

از اساتيد محترم گروه آناتومى دانشكده يزشكى به بهاس

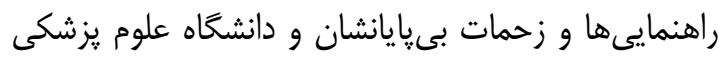

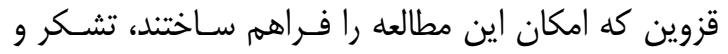

$$
\text { قدردانى مىنماييه. }
$$

\section{مراجع:}

1. Foster ER, Black KJ, Antenor-Dorsey JA, Perlmutter JS, Hershey T. Motor asymmetry and substantia nigra volume are related to spatial delayed response performance in Parkinson's disease. Brain Cogn 2008; 67(1): 110. doi: 10.1016/j.bandc.2007.10.002.
ا را بيان مى كنند.(\$9) در مغز ميانى مـدل PD-i

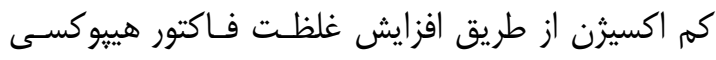

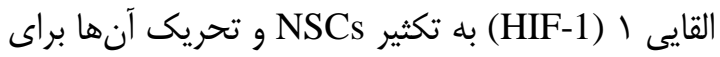

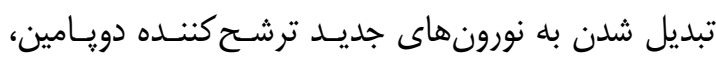

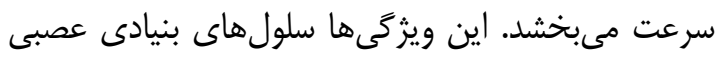

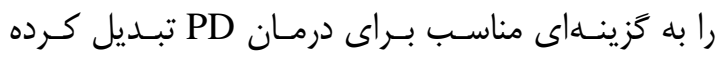

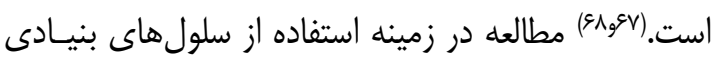

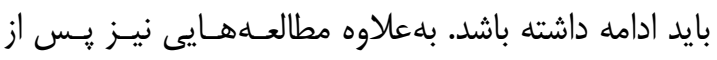

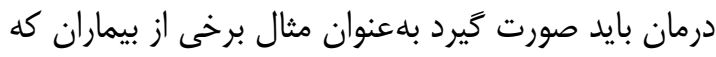

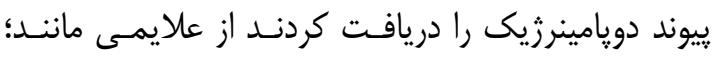

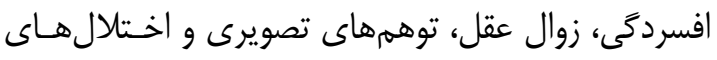

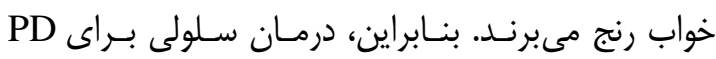

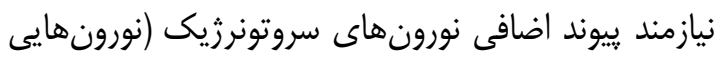

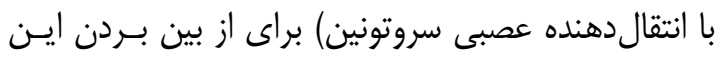

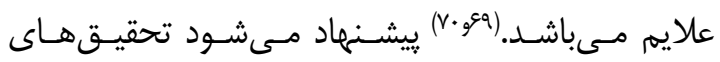

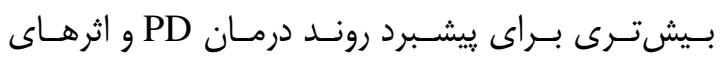

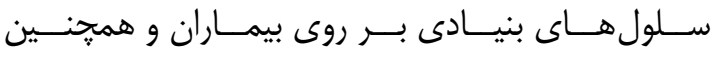

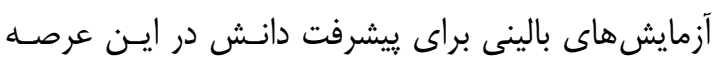
حياتى انجام شود. با توجه به مكانيسمهاى ناشناخته يار كينسـون، هنـوز

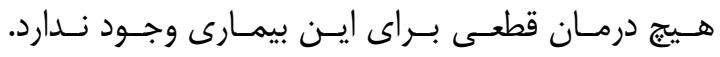
انتظارهاى زيادى در زمينه درمان سلولهاى بن بنيادى برى براى

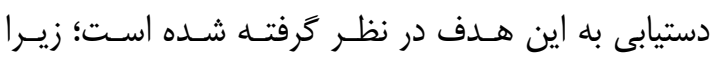

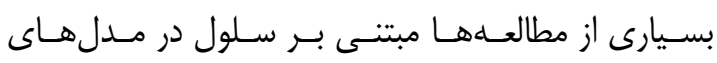
حيوانى PD نتايج مثبت نشان دادهاند.

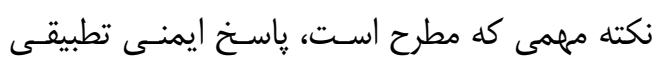

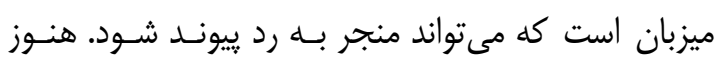

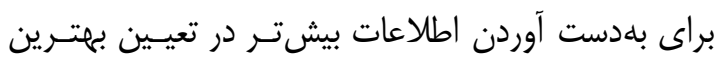

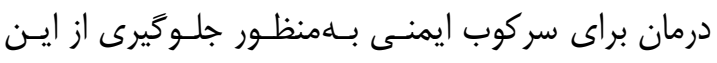

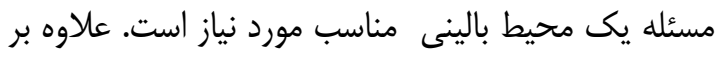

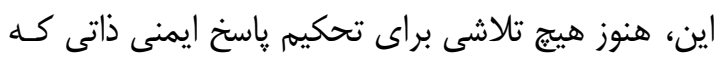

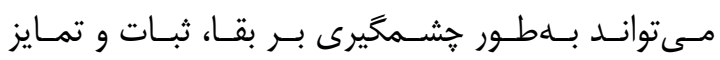

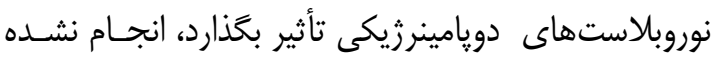
است. با در نظر كرفتن متغيرهايى كه بر اين فراينـد تـأثير 
2. Faghihi A, Joghataie MT, Darabi S, Mehdizadeh M, Roghani M, Bakhtiari M. Evaluation of behavioral effects of transresveratrol in the hemi parkinsonian rat model. J Iranian Anatomical Sciences 2007; 5(19): 107-14.

3. Rangel-Barajas C, Coronel I, Florán B. Dopamine receptors and neurodegeneration. Aging Dis 2015; 6(5): 349-68. doi: 10.14336/ AD.2015.0330.

4. Zhang J, Wang X, Li J, Huang R, Yu X, Dong $\mathrm{C}$, et al. The Preclinical research progress of stem cells therapy in Parkinson's disease. Biomed Res Int 2016; 2016: 5683097. doi: 10.1155/2016/5683097.

5. Jankovic J. Parkinson's disease: clinical features and diagnosis. J Neurol Neurosurg Psychiatry 2008; 79(4): 368-76. doi: 10.1136/jnnp.2007. 131045.

6. Shams Nooraei M, Noori-Zadeh A, Darabi

S, Rajaei F, Golmohammadi Z, Abbaszadeh HA. Low level of autophagy-related gene 10 (ATG10) expression in the 6Hydroxydopamine rat model of Parkinson's disease. Iran Biomed J 2018; 22(1): 15-21. doi: 10.22034/ibj.22.1.15.

7. Choi H, Koh SH. Understanding the role of glycogen synthase kinase-3 in L-DOPAinduced dyskinesia in Parkinson's disease. Expert Opin Drug Metab Toxicol 2018; 14(1): 83-90. doi: 10.1080/17425255.2018. 1417387.

8. Darabi S, Tiraihi T, Delshad A, Sadeghizadeh M, Khalil W, Taheri T. In vitro non-viral murine pro-neurotrophin 3 gene transfer into rat bone marrow stromal cells. $\mathrm{J}$ Neurol Sci 2017; 375: 137-45. doi: 10.1016/j. jns.2017.01.058.

9. Morizane A, Takahashi J. Cell therapy for Parkinson's disease. Nihon Yakurigaku Zasshi 2016; 147(5): 264-8. doi: 10.1254/fpj.
147.264.

10. Cho MS, Hwang DY, Kim DW. Efficient derivation of functional dopaminergic neurons from human embryonic stem cells on a large scale. Nat Protoc 2008; 3(12): 188894. doi: 10.1038/nprot.2008.188.

11. Volarevic V, Markovic BS, Gazdic M, Volarevic A, Jovicic N, Arsenijevic N, et al. Ethical and safety issues of stem cell-based therapy. Int J Med Sci 2018; 15(1): 36-45. doi: 10.7150/ijms.21666.

12. Sanchez-Pernaute R, Studer L, Ferrari D, Perrier A, Lee H, Vinuela A, et al. Long-term survival of dopamine neurons derived from parthenogenetic primate embryonic stem cells (cyno-1) after transplantation. Stem Cells 2005; 23(7): 914-22. doi: 10.1634/stemcells. 2004-0172.

13. Brundin $\mathrm{P}$, Nilsson $\mathrm{OG}$, Gage $\mathrm{FH}$, Björklund A. Cyclosporin A increases survival of cross-species intrastriatal grafts of embryonic dopamine-containing neurons. Exp Brain Res 1985; 60(1): 204-8.

14. Larsson LC, Frielingsdorf H, Mirza B, Hansson SJ, Anderson P, Czech KA, et al. Porcine neural xenografts in rats and mice: donor tissue development and characteristics of rejection. Exp Neurol 2001; 172(1): 10014. doi: 10.1006/exnr.2001.7738.

15. Takagi Y, Takahashi J, Saiki H, Morizane A, Hayashi T, Kishi Y, et al. Dopaminergic neurons generated from monkey embryonic stem cells function in a Parkinson primate model. J Clin Invest 2005; 115(1): 102-9. doi: 10.1172/JCI200521137.

16. Itoh $\mathrm{N}$, Ohta $\mathrm{H}$. Roles of FGF20 in dopaminergic neurons and Parkinson's disease. Front Mol Neurosci 2013; 6: 15. doi: 10.3389/fnmol.2013.00015.

17. Hedlund E, Pruszak J, Ferree A, Vinuela A, Hong S, Isacson $\mathrm{O}$, et al. Selection of 
embryonic stem cell-derived enhanced green fluorescent protein-positive dopamine neurons using the tyrosine hydroxylase promoter is confounded by reporter gene expression in immature cell populations. Stem Cells 2007; 25(5): 1126-35. doi: 10 . 1634/stemcells.2006-0540.

18. Hong S, Chung S, Leung K, Hwang I, Moon J, Kim KS. Functional roles of Nurr1, Pitx3, and Lmx1a in neurogenesis and phenotype specification of dopamine neurons during in vitro differentiation of embryonic stem cells. Stem Cells Dev 2014; 23(5): 47787. doi: 10.1089/scd.2013.0406.

19. Tatard VM, Sindji L, Branton JG, AubertPouessel A, Colleau J, Benoit JP, et al. Pharmacologically active microcarriers releasing glial cell line - derived neurotrophic factor: Survival and differentiation of embryonic dopaminergic neurons after grafting in hemiparkinsonian rats. Biomaterials 2007; 28(11): 1978-88. doi :10. 1016/j.biomaterials.2006.12.021.

20. Espejo M, Cutillas B, Arenas TE, Ambrosio S. Increased survival of dopaminergic neurons in striatal grafts of fetal ventral mesencephalic cells exposed to neurotrophin-3 or glial cell line-derived neurotrophic factor. Cell Transplant 2000; 9(1): 4553.

21. Perez-Bouza A, Di Santo S, Seiler S, Meyer M, Andereggen L, Huber A, et al. Simultaneous transplantation of fetal ventral mesencephalic tissue and encapsulated genetically modified cells releasing GDNF in a hemi-parkinsonian rat model of Parkinson's disease. Cell Transplant 2017; 26(9): 157281. doi: $10.1177 / 0963689717721202$.

22. Preynat-Seauve O, de Rham C, Tirefort D, Ferrari-Lacraz S, Krause KH, Villard J. Neural progenitors derived from human embryonic stem cells are targeted by allogeneic $\mathrm{T}$ and natural killer cells. J Cell Mol Med 2009; 13(9B): 3556-69. doi: 10. 1111/j.1582-4934.2009.00746.x.

23. Mirza B, Krook H, Andersson P, Larsson LC, Korsgren $\mathrm{O}$, Widner $\mathrm{H}$. Intracerebral cytokine profiles in adult rats grafted with neural tissue of different immunological disparity. Brain Res Bull 2004; 63(2): 105-18. doi: 10.1016/j.brainresbull.2004.01.009.

24. Spenger C, Haque NS, Studer L, Evtouchenko L, Wagner B, Bühler B, et al. Fetal ventral mesencephalon of human and rat origin maintained in vitro and transplanted to 6-hydroxydopamine-lesioned rats gives rise to grafts rich in dopaminergic neurons. Exp Brain Res 1996; 112(1): 47-57.

25. Kurowska Z, Englund E, Widner $\mathrm{H}$, Lindvall $\mathrm{O}, \mathrm{Li} \mathrm{J}-\mathrm{Y}$, Brundin P. Signs of degeneration in 12-22-year old grafts of mesencephalic dopamine neurons in patients with Parkinson's disease. J Parkinsons Dis 2011; 1(1): 83-92. doi: 10.3233/JPD-201111004.

26. Seghatoleslam M, Hosseini M. Potential of stem cells in the treatment OF nervous system disorders. Shefaye Khatam 2015; 3(1): 99-114 . [In Persian]

27. Barachini S, Trombi L, Danti S, D'Alessandro D, Battolla B, Legitimo A, et al. Morpho-functional characterization of human mesenchymal stem cells from umbilical cord blood for potential uses in regenerative medicine. Stem Cells Dev 2009; 18(2): 293-305. doi: 10.1089/scd.2008.0017. 28. Abd Elhalem SS, Haggag NZ, ElShinnawy NA. Bone marrow mesenchymal stem cells suppress IL-9 in adjuvant-induced arthritis. Autoimmunity 2018; 51(1): 25-34. doi: 10.1080/08916934.2018.1428956.

29. Enciso N, Ostronoff LLK, Mejias G, Leon LG, Fermin ML, Merino E, et al. Stem 
cell factor supports migration in canine mesenchymal stem cells. Vet Res Commun 2018; 42(1):29-38. doi: 10.1007/s11259-0179705-x.

30. Moradian $H$, Keshvari $H$, Fasehee $H$, Dinarvand R, Faghihi S. Combining NT3overexpressing MSCs and PLGA microcarriers for brain tissue engineering: A potential tool for treatment of Parkinson's disease. Mater Sci Eng C Mater Biol Appl 2017; 76: 934-43. doi: 10.1016/j.msec.2017. 02.178 .

31. Morandi F, Raffaghello L, Bianchi G, Meloni F, Salis A, Millo E, et al. Immunogenicity of human mesenchymal stem cells in HLA-class I-restricted T-cell responses against viral or tumor-associated antigens. Stem Cells 2008; 26(5): 1275-87. doi: 10.1634/stemcells.2007-0878.

32. Talwadekar MD, Kale VP, Limaye LS. Placenta-derived mesenchymal stem cells possess better immunoregulatory properties compared to their cord-derived counterparts-a paired sample study. Sci Rep 2015; 5: 15784. doi: 10.1038/srep15784.

33. Kim JY, Jeon HB, Yang YS, Oh W, Chang JW. Application of human umbilical cord blood-derived mesenchymal stem cells in disease models. World J Stem Cells 2010; 2(2): 34-8. doi: 10.4252/wjsc.v2.i2.34.

34. Yan M, Sun M, Zhou Y, Wang W, He Z, Tang D, et al. Conversion of human umbilical cord mesenchymal stem cells in Wharton's jelly to dopamine neurons mediated by the Lmx1a and neurturin in vitro: potential therapeutic application for Parkinson's disease in a rhesus monkey model. PLoS One 2013; 8(5): e64000. doi: 10.1371/journal.pone. 0064000.

35. Liu XS, Li JF, Wang SS, Wang YT, Zhang YZ, Yin HL, et al. Human umbilical cord mesenchymal stem cells infected with adenovirus expressing HGF promote regeneration of damaged neuron cells in a Parkinson's disease model. Biomed Res Int 2014; 2014: 909657. doi: 10.1155/2014/ 909657.

36. Khoo ML, Tao H, Meedeniya AC, Mackay-Sim A, Ma DD. Transplantation of neuronal-primed human bone marrow mesenchymal stem cells in hemiparkinsonian rodents. PLoS One 2011; 6(5): e19025. doi: 10.1371/journal.pone.0019025.

37. Ahmed HH, Salem AM, Atta HM, Eskandar EF, Farrag AR, Ghazy MA, et al. Updates in the pathophysiological mechanisms of Parkinson's disease: Emerging role of bone marrow mesenchymal stem cells. World J Stem Cells 2016; 8(3): 106-17. doi: 10.4252/wjsc.v8.i3.106.

38. Borlongan CV, Glover LE, Tajiri N, Kaneko Y, Freeman TB. The great migration of bone marrow-derived stem cells toward the ischemic brain: therapeutic implications for stroke and other neurological disorders. Prog Neurobiol 2011; 95(2): 213-28. doi: 10.1016/ j.pneurobio.2011.08.005.

39. Jiaming $\mathrm{M}$, Niu C. Comparing neuroprotective effects of CDNF-expressing bone marrow derived mesenchymal stem cells via differing routes of administration utilizing an in vivo model of Parkinson's disease. Neurol Sci 2015; 36(2): 281-7. doi: 10.1007/s10072-014-1929-8.

40. Chen D, Fu W, Zhuang W, Lv C, Li F, Wang X. Therapeutic effects of intranigral transplantation of mesenchymal stem cells in rat models of Parkinson's disease. J Neurosci Res 2017; 95(3): 907-17. doi: 10.1002/jnr. 23879.

41. Mohammad-Gharibani P, Tiraihi T, Arabkheradmand J. In vitro transdifferentiation of 
bone marrow stromal cells into GABAergiclike neurons. Iran Biomed J 2009; 13(3): 137-43. 42. Beane OS, Fonseca VC, Cooper LL, Koren G, Darling EM. Impact of aging on the regenerative properties of bone marrow,muscle-, and adipose-derived mesenchymal stem/stromal cells. PloS One 2014; 9(12): e115963. doi: 10.1371/journal.pone.0115963. 43. Schwerk A, Altschuler J, Roch M, Gossen M, Winter C, Berg J, et al. Adipose-derived human mesenchymal stem cells induce longterm neurogenic and anti-inflammatory effects and improve cognitive but not motor performance in a rat model of Parkinson's disease. Regen Med 2015; 10(4): 431-46. doi: 10.2217/rme.15.17.

44. Ahmed H, Salem A, Atta H, Ghazy M, Aglan H. Do adipose tissue-derived mesenchymal stem cells ameliorate Parkinson's disease in rat model? Hum Exp Toxicol 2014; 33(12): 1217-31. doi: 10.1177/ 0960327114524238.

45. Chen X, Yan L, Guo Z, Chen Z, Chen Y, $\mathrm{Li} \mathrm{M}$, et al. Adipose-derived mesenchymal stem cells promote the survival of fat grafts via crosstalk between the Nrf2 and TLR4 pathways. Cell Death Dis 2016: (9)7; e2369. doi: 10.1038/cddis.2016.261.

46. Zhou Y, Sun M, Li H, Yan M, He Z, Wang W, et al. Recovery of behavioral symptoms in hemi-parkinsonian rhesus monkeys through combined gene and stem cell therapy. Cytotherapy 2013; 15(4): 46780. doi: 10.1016/j.jcyt.2013.01.007.

47. Heo JS, Choi Y, Kim HS, Kim HO. Comparison of molecular profiles of human mesenchymal stem cells derived from bone marrow, umbilical cord blood, placenta and adipose tissue. Int $\mathrm{J}$ Mol Med 2016; 37(1): 115-25. doi: 10.3892/ijmm.2015.2413.

48. Mohanty V, Shah A, Allender E, Siddiqui
MR, Monick S, Ichi S, et al. Folate receptor Alpha upregulates Oct4, Sox 2 and Klf4 and downregulates miR-138 and miR-let-7 in cranial neural crest cells. Stem Cells 2016; 34(11): 2721-32. doi: 10.1002/stem.2421.

49. Choi HS, Kim HJ, Oh JH, Park HG, Ra JC, Chang KA, et al. Therapeutic potentials of human adipose-derived stem cells on the mouse model of Parkinson's disease. Neurobiol Aging 2015; 36(10): 2885-92. doi: 10.1016/j.neurobiolaging.2015.06.022.

50. Deane JA, Gualano RC, Gargett CE. Regenerating endometrium from stem/progenitor cells: is it abnormal in endometriosis, Asherman's syndrome and infertility? Curr Opin Obstet Gynecol 2013; 25(3): 193-200. doi: 10.1097/GCO. $0 \mathrm{~b} 013 \mathrm{e} 32836024 \mathrm{e} 7$.

51. Mutlu L, Hufnagel D, Taylor HS. The endometrium as a source of mesenchymal stem cells for regenerative medicine. Biol Reprod 2015; 92(6): 138. doi: 10.1095/ biolreprod.114.126771.

52. Gargett CE, Schwab KE, Deane JA. Endometrial stem/progenitor cells: the first 10 years. Hum Reprod Update 2016; 22(2): 13763. doi: 10.1093/humupd/dmv051.

53. Wolff EF, Mutlu L, Massasa EE, Elsworth JD, Eugene Redmond D, Taylor HS. Endometrial stem cell transplantation in MPTP-exposed primates: an alternative cell source for treatment of Parkinson's disease. J Cell Mol Med 2015; 19(1): 249-56. doi: 10. 1111/jcmm.12433.

54. Wolff EF, Gao XB, Yao KV, Andrews $\mathrm{ZB}, \mathrm{Du} \mathrm{H}$, Elsworth JD, et al. Endometrial stem cell transplantation restores dopamine production in a Parkinson's disease model. J Cell Mol Med 2011; 15(4): 747-55. doi: 10. 1111/j.1582-4934.2010.01068.x. 
55. Zhang D, Yang S, Toledo EM, Gyllborg D, Salto C, Carlos Villaescusa J, et al. Nichederived laminin-511 promotes midbrain dopaminergic neuron survival and differentiation through YAP. Sci Signal 2017; 10(493). pii: eaal4165. doi: 10.1126/scisignal. aal4165.

56. Vishwakarma SK ,Bardia A, Tiwari SK, Paspala SA, Khan AA. Current concept in neural regeneration research: NSCs isolation, characterization and transplantation in various neurodegenerative diseases and stroke: a review. J Adv Res 2014; 5(3): 277-94. doi: 10. 1016/j.jare.2013.04.005.

57.Behrstock S, Ebert A, McHugh J, Vosberg S, Moore J, Schneider B, et al. Human neural progenitors deliver glial cell line-derived neurotrophic factor to parkinsonian rodents and aged primates. Gene Ther 2006; 13(5): 379-88. doi: 10.1038/sj.gt. 3302679.

58. Bjugstad KB, Teng YD, Redmond DE Jr, Elsworth JD, Roth RH, Cornelius SK, et al. Human neural stem cells migrate along the nigrostriatal pathway in a primate model of Parkinson's disease. Exp Neurol 2008; 211(2): 362-9. doi: 10.1016/j.expneurol. 2008.01.025.

59. Johnston TH, Fox SH, Mclldowie MJ, Piggott MJ, Brotchie JM. Reduction of LDOPA-induced dyskinesia by the selective metabotropic glutamate receptor 5 antagonist 3- [(2-methyl-1, 3-thiazol-4-yl) ethynyl] pyridine in the 1-methyl-4-phenyl-1,2,3,6tetrahydropyridine-lesioned macaque model 60. Leiphart JW, Valone FH 3rd. Stereotactic lesions for the treatment of psychiatric disorders. J Neurosurg 2010; 113(6): 120411. doi: 10.3171/2010.5.JNS091277.

61. Salama M, Sobh M, Emam M, Abdalla A, Sabry D, El-Gamal M, et al. Effect of intranasal stem cell administration on the nigrostriatal system in a mouse model of Parkinson's disease. Exp Ther Med 2017; 13(3): 976-82. doi: 10.3892/etm.2017.4073.

62. Boroujeni ME, Gardaneh M. Umbilical cord: an unlimited source of cells differentiable towards dopaminergic neurons. Neural Regen Res 2017; 12(7): 1186-92. doi: 10.4103/1673-5374.211201.

63.Ishii T, Eto K. Fetal stem cell transplantation: Past, present, and future. World J Stem Cells 2014; 6(4): 404-20. doi: 10.4252/wjsc.v6.i4.404.

64. Wang Y, Tien LT, Lapchak PA, Hoffer BJ. GDNF triggers fiber outgrowth of fetal ventral mesencephalic grafts from nigra to striatum in 6-OHDA-lesioned rats. Cell Tissue Res 1996; 286(2): 225-33.

65. Morrison SJ. Neuronal potential and lineage determination by neural stem cells. Curr Opin Cell Biol 2001; 13(6): 666-72. doi: 10.1016/S0955-0674(00)00269-6.

66. Pardal R, Lopez-Barneo J. Neural stem cells and transplantation studies in Parkinson's disease. Adv Exp Med Biol 2012; 741: 206-16. doi: 10.1007/978-1-4614-20989_14.

67. Ourednik J, Ourednik V, Lynch WP, Schachner M, Snyder EY. Neural stem cells display an inherent mechanism for rescuing dysfunctional neurons. Nat Biotechnol 2002; 20(11): 1103-10.

68. Xiao JJ, Yin M, Wang ZJ, Wang XP. Transplanted neural stem cells: playing a neuroprotective role by ceruloplasmin in the substantia nigra of PD model rats? Oxid Med Cell Longev 2015; 2015: 618631. doi: 10. 1155/2015/618631.

69.Miguelez C, Navailles S ,De Deurwaerdere P, Ugedo L. The acute and long-term L-DOPA effects are independent from changes in the activity of dorsal raphe 
serotonergic neurons in 6-OHDA lesioned rats. Br J Pharmacol 2016; 173(13): 2135-46. doi: 10.1111/bph.13447.

70. Grosch J, Winkler J, Kohl Z. Early degeneration of both dopaminergic and serotonergic axons-a common mechanism in Parkinson's disease. Front Cell Neurosci 2016; 10: 293. doi: 10.3389/fncel.2016. 00293.
71. Zhang J, Wang X, Li J, Huang R, Yu X, Dong $\mathrm{C}$, et al. The preclinical research progress of Stem cells therapy in Parkinson's disease. Biomed Res Int 2016; 2016: 5683097. doi: 10.1155/2016/5683097.

72. Lindvall O. Treatment of Parkinson's disease using cell transplantation. Philos Trans R Soc Land B Biol Sci 2015; 370(1680): 20140370. doi: 10.1098/rstb. 2014.0370 . 